\title{
Complex and liquid hydrides for energy storage
}

\author{
Elsa Callini $^{1,2} \cdot$ Zuleyha Özlem Kocabas Atakli $^{2} \cdot$ Bjørn C. Hauback ${ }^{3}$. \\ Shin-ichi Orimo ${ }^{12}$. Craig Jensen ${ }^{13} \cdot$ Martin Dornheim $^{10}$ • David Grant ${ }^{11}$. \\ Young Whan Cho ${ }^{9}$ - Ping Chen ${ }^{7}$ - Bjørgvin Hjörvarsson ${ }^{14}$ - Petra de Jongh ${ }^{6}$. \\ Claudia Weidenthaler ${ }^{15} \cdot$ Marcello Baricco $^{4} \cdot$ Mark Paskevicius $^{5} \cdot$ Torben R. Jensen $^{5}$. \\ Mark E. Bowden ${ }^{8}$ Thomas S. Autrey ${ }^{8}$ Andreas Züttel ${ }^{1,2}$
}

Received: 1 September 2015/Accepted: 17 November 2015/Published online: 10 March 2016

(c) Springer-Verlag Berlin Heidelberg 2016

\begin{abstract}
The research on complex hydrides for hydrogen storage was initiated by the discovery of $\mathrm{Ti}$ as a hydrogen sorption catalyst in $\mathrm{NaAlH}_{4}$ by Boris Bogdanovic in 1996. A large number of new complex hydride materials in various forms and combinations have been synthesized and characterized, and the knowledge regarding the properties of complex hydrides and the synthesis methods has grown enormously since then. A significant portion of the research groups active in the field of complex hydrides is collaborators in the International Energy Agreement Task 32. This paper reports about the important issues in the field of complex hydride research, i.e. the synthesis of borohydrides, the thermodynamics of complex hydrides,
\end{abstract}

Andreas Züttel

andreas.zuettel@epfl.ch

1 Laboratory of Materials for Renewable Energy (LMER), Institute of Chemical Sciences and Engineering (ISIC), École polytechnique fédérale de Lausanne, EPFL Valais/Wallis, Sion, Switzerland

2 EMPA Materials Science and Technology, Überlandstrasse 129, 8600 Sion, Switzerland

3 Physics Department, Institute for Energy Technology, Kjeller, Norway

4 Department of Chemistry and NIS, University of Turin, Turin, Italy

5 Department of Chemistry, Center for Materials Crystallography, Interdisciplinary Nanoscience Center, Aarhus University, Langelandsgade 140, 8000 Aarhus C, Denmark

6 Debye Institute for Nanomaterials Science, Utrecht University, Universiteitsweg 99, 3584 CG Utrecht, The Netherlands

7 Dalian Institute of Chemical Physics, Chinese Academy of Sciences, Dalian 116023, China the effects of size and confinement, the hydrogen sorption mechanism and the complex hydride composites as well as the properties of liquid complex hydrides. This paper is the result of the collaboration of several groups and is an excellent summary of the recent achievements.

\section{Introduction}

Hydrogen storage is the main challenge of the hydrogen cycle, a closed loop that includes hydrogen production, storage and use. Such a cycle allows for storing hydrogen produced by renewable energy and does not contain carbon

$8 \quad$ Pacific Northwest National Laboratory, 902 Battelle Boulevard, P.O. Box 999, Richland, WA 99352, USA

9 Future Convergence Research Division, High Temperature Energy Materials Research Center, Korea Institute of Science and Technology, Hwarangno 14-gil 5, Seongbuk-gu, Seoul 136-791, Republic of Korea

10 Department of Nanotechnology, Materials Technology, Helmholtz-Zentrum Geesthacht, Geesthacht, Germany

11 University Park, Nottingham NG7 2RD, UK

12 WPI Advanced Institute for Materials Research (WPIAIMR), Institute for Materials Research, Tohoku University, Sendai, Japan

13 Department of Chemistry, University of Hawaii at Manoa, 2545 The Mall, Honolulu, HI 96822-2275, USA

14 Department of Physics and Astronomy, Materials Physics, Box 516, 75120 Uppsala, Sweden

15 Department of Heterogeneous Catalysis, Max-Planck-Institut für Kohlenforschung, Kaiser-Wilhelm-Platz 1, 45470 Mülheim an der Ruhr, Germany 
$\left(\mathrm{CO}_{2}\right.$ neutral). Hydrogen is the most promising candidate for store energy [1], as it is the most abundant element in the universe. Hydrogen can be produced in large quantities from water on demand and represents a solution to the fluctuation in energy collection. Finding a material that allows for storing hydrogen with high hydrogen density and fast hydrogen sorption kinetics [2-4] is requested by most applications, and, therefore, several options are under consideration. Liquefied hydrogen, pressurized tanks, metal hydrides and complex hydrides have been intensively investigated. However, the interactions of the hydrogen molecules or atoms with solid materials or surfaces are not well known on an atomic level in complex hydrides. The identification of the decomposition reaction pathways of several complex hydrides, the determination of the intermediate species in dehydrogenation reactions, the emission of side products and the role of catalysts are all challenges [5] that require the most advanced characterization instruments and a profound knowledge of the chemical physics of gas-solid interactions.

The International Energy Agency (IEA) Task 32 " $\mathrm{H}_{2}$ Based Energy Storage" addresses hydrogen-based energy storage by developing reversible or regenerative hydrogen storage materials.

In the materials under consideration, the quantitative targets for hydrogen capacities vary significantly depending on the different applications; for example, the gravimetric density is crucial for mobile applications, whereas in stationary systems, it plays a minor role [6-9]. Therefore, for each specific application, the targets related to volumetric density, thermodynamics, kinetics, cost and safety are different. A fundamental understanding of hydrogen storage mechanisms is the key to a breakthrough in the development of materials with improved properties. The focus within this task is on hydrogen in solid compounds approached by complimentary experimental, engineering and modelling (both scientific and engineering) activities. At present, Task 32 consists of 48 R\&D projects led by project leaders from the participating countries. Most projects involve international collaborations, which are strongly encouraged. The projects are divided into five working groups:

- Porous materials (coordination polymer framework compounds, metal organic frameworks, zeolitic imidazolate frameworks, covalent organic frameworks and carbon-based compounds)

- Magnesium-based hydrogen and energy storage materials

- Complex and liquid hydrides (borohydrides, alanates, amides/imides systems, magnesium-based compounds, reactive hydride composites and rechargeable liquid hydrogen carriers)
- Electrochemical storage of energy (MH batteries, ion conduction)

- Heat storage-concentrated solar thermal using metal hydrides

The following countries contribute to Task 32, " $\mathrm{H}_{2}$ Based Energy Storage": Australia, Denmark, France, Germany, Greece, Israel, Italy, Japan, Lithuania, Netherlands, Norway, Korea, Sweden, Switzerland, the UK and the USA.

In this paper, we report the recent achievements of the workgroup "Complex and Liquid Hydrides." We present the synthesis routes of novel metal borohydrides, an empirical model for the stability of the alanates and borohydrides, the reaction mechanism for the hydrogen desorption from alanates and borohydrides, the impact of nanoconfinement on the hydrogen sorption properties, the properties of the reactive composite hydrides and the synthesis and characterization of liquid hydrides.

\section{Synthesis of novel borohydrides}

Mechanochemistry (more commonly known as ball milling) is one of the most common methods for the preparation of novel metal borohydrides [15]. A variety of reactions can occur, and in some cases, several competing reactions are observed simultaneously. Metathesis, or a double substitution reaction, is a well-known mechanism for chemical reactions during ball milling, here illustrated by a reaction in the system, $\mathrm{YCl}_{3}-\mathrm{LiBH}_{4}$ (1:3), which results in the formation of $\mathrm{Y}\left(\mathrm{BH}_{4}\right)_{3}$ and $\mathrm{LiCl}$, according to Eq. 1 [10-14].

$\mathrm{YCl}_{3}+3 \mathrm{LiBH}_{4} \rightarrow \mathrm{Y}\left(\mathrm{BH}_{4}\right)_{3}+3 \mathrm{LiCl}$

In more rare cases, addition reactions occur, and a pure product can be obtained, e.g. the synthesis of $\mathrm{KZn}\left(\mathrm{BH}_{4}\right) \mathrm{Cl}_{2}$ (see Eq. 2) [15, 16].

$\mathrm{ZnCl}_{2}+\mathrm{KBH}_{4} \rightarrow \mathrm{KZn}\left(\mathrm{BH}_{4}\right) \mathrm{Cl}_{2}$

$\mathrm{KZn}\left(\mathrm{BH}_{4}\right) \mathrm{Cl}_{2}$ contains the first observation of a heteroleptic complex ion containing $\mathrm{BH}_{4}{ }^{-}$as a ligand, i.e. $\left[\mathrm{Zn}\left(\mathrm{BH}_{4}\right) \mathrm{Cl}_{2}\right]^{-}$, where $\mathrm{Zn}$ coordinates to two chloride ions and two hydrogen atoms in $\eta^{2}-\mathrm{BH}_{4}, \mathrm{Cl}(\mathrm{Zn})=4$ [15]. This clearly demonstrates that mechanochemistry can induce complex chemical reactions involving bond breaking and bond formation [16]. The first example of a mixed metal borohydride was $\mathrm{LiSc}\left(\mathrm{BH}_{4}\right)_{4}$ [17]. The mechanochemical synthesis of other new borohydrides in the system $\mathrm{ZnCl}_{2}-$ $\mathrm{MBH}_{4}$, e.g. $\mathrm{NaZn}_{2}\left(\mathrm{BH}_{4}\right)_{5}$, proceeds via more complex chemical reactions during ball milling-possibly a combination of metathesis and addition reactions [18, 19]. Surprisingly, these observations suggest that ball milling 
may lead to a state of chemical equilibrium rather than just a statistical distribution of reactants as expected, e.g. for the mechanical alloying of metals.

Reaction scheme (1) also illustrates a general drawback of the mechanochemical approach involving metathesis reactions, namely contamination of products by ionic compounds, e.g. binary or ternary metal halides [19]. Furthermore, the presence of halides during the synthesis of metal borohydrides tends to hamper reversible hydrogen storage due to the formation of bimetallic halides during thermal decomposition.

A novel technique for reactive ball milling under a diborane atmosphere was developed, allowing solvent-free synthesis of borohydrides at room temperature, demonstrated by the synthesis of, e.g. $\mathrm{LiBH}_{4}, \mathrm{Li}_{2} \mathrm{~B}_{12} \mathrm{H}_{12}, \mathrm{Li}_{2-}$ $\mathrm{B}_{10} \mathrm{H}_{10}, \mathrm{Mg}\left(\mathrm{BH}_{4}\right)_{2}, \mathrm{MgB}_{12} \mathrm{H}_{12}$ and $\mathrm{Ca}\left(\mathrm{BH}_{4}\right)_{2}$ [20-24]. Similarly, $\mathrm{Y}\left(\mathrm{BH}_{4}\right)_{3}$ was prepared in a reaction between $\mathrm{YH}_{3}$ and $\mathrm{B}_{2} \mathrm{H}_{6}$ [25]. This new gas-solid mechanochemical synthesis method is based on the reaction of metal hydrides with diborane to form the corresponding borohydrides or higher boranes, which may facilitate preparation of a range of other metal borohydrides in the future. In a similar manner, amorphous $\mathrm{Mg}\left(\mathrm{BH}_{4}\right)_{2}$ can also be prepared by ball milling $\mathrm{MgB}_{2}$ in a hydrogen atmosphere [26].

An alternative approach is to combine solvent-based synthesis methods with mechanochemistry. Solvent-based methods can provide a solvent-free monometallic borohydride, often by using a metal borohydride solvate as an intermediate, such as $M\left(\mathrm{BH}_{4}\right)_{\mathrm{x}}, M=\mathrm{Mg}, \mathrm{Mn}, \mathrm{Y}, \mathrm{Eu}, \mathrm{Gd}$ [27-31]. This approach has also led to the first tri-metallic borohydrides [32-34].

Synthesis of a series of solvent- and halide-free ammine rare-earth metal borohydrides $M\left(\mathrm{BH}_{4}\right)_{3} \cdot n \mathrm{NH}_{3}, M=\mathrm{Y}, \mathrm{Gd}$, Dy; $n=7,6,5,4,2$ and 1 and $\mathrm{Mn}\left(\mathrm{BH}_{4}\right)_{2} \cdot n \mathrm{NH}_{3}, n=1,2$, 3 , and 6 , via a new approach has recently been conducted, combining mechanochemistry, solvent-based methods, solid-gas reactions and thermal treatment $[35,36]$.

\subsection{Metal borohydride halides}

Three classes of metal borohydride chlorides with fully ordered structures have been identified so far: the mono metallic borohydride halide $\mathrm{Sr}\left(\mathrm{BH}_{4}\right) \mathrm{Cl}$ [37], bimetallic $\mathrm{KZn}\left(\mathrm{BH}_{4}\right) \mathrm{Cl}_{2}[15]$ and rare earth containing $\mathrm{Li} M\left(\mathrm{BH}_{4}\right)_{3} \mathrm{Cl}$, $M=\mathrm{La}, \mathrm{Ce}, \mathrm{Pr}, \mathrm{Nd}, \mathrm{Gd}$, and Sm [38-42]. The latter has an interesting structure and contains isolated tetranuclear anionic clusters $\left[\mathrm{M}_{4} \mathrm{Cl}_{4}\left(\mathrm{BH}_{4}\right)_{12}\right]^{4-}$ with a distorted cubane $\mathrm{M}_{4} \mathrm{Cl}_{4}$ core, counterbalanced by $\mathrm{Li}^{+}$cations. Mixed-cation mixed-anion borohydrides with disordered structures are also observed; for example, sodium yttrium borohydride has the ideal composition $\mathrm{NaY}\left(\mathrm{BH}_{4}\right)_{2} \mathrm{Cl}_{2}$, with some $\mathrm{Cl}$ substitution into the $\mathrm{BH}_{4}$ site resulting in $\mathrm{NaY}\left(\mathrm{BH}_{4}\right)_{1.79}$ $\mathrm{Cl}_{2.21}$ [43]. Hence, this structure can be considered as partly ordered. In the $\mathrm{Li}-\mathrm{Yb}-\mathrm{BH}_{4}$ system, two intermediate phases are observed without lithium: $\mathrm{Yb}\left(\mathrm{BH}_{4}\right)_{1.26} \mathrm{Cl}_{0.74}$ with space group $P-4$ and isostructural to $\beta-\mathrm{Ca}\left(\mathrm{BH}_{4}\right)_{2}$ and $\mathrm{Yb}\left(\mathrm{BH}_{4}\right)_{1.7} \mathrm{Cl}_{0.3}$ with space group $\mathrm{Pbca}$ and isostructural to $\gamma-\mathrm{Ca}\left(\mathrm{BH}_{4}\right)_{2}$ [44]. Furthermore, substitution of $\mathrm{BH}_{4}{ }^{-}$with $\mathrm{Cl}^{-}$can also take place in the novel metal borohydrides formed during mechanochemical synthesis; for example, Rietveld refinement suggests incorporation of $\sim 42 \mathrm{~mol} \%$ of $\mathrm{Cl}^{-}$on one of the two $\mathrm{BH}_{4}{ }^{-}$sites in $\mathrm{Al}_{3} \mathrm{Li}_{4}\left(\mathrm{BH}_{4}\right)_{13}$ [45].

\subsection{Anion substitution in metal borohydrides}

Anion substitution is a relatively new method for tailoring the properties of known metal borohydrides. Substitution of $\mathrm{BH}_{4}{ }^{-}$or $\mathrm{H}^{-}$by anions with the same charge and comparable size may lead to the formation of solid solutions. Table 1 shows that the $\mathrm{BH}_{4}{ }^{-}$complex anion may be substituted with the heavier halides, $\mathrm{Cl}^{-}, \mathrm{Br}^{-}$or $\mathrm{I}^{-}$, and that the $\mathrm{H}^{-}$anion may be substituted with $\mathrm{F}^{-}$.

Initially, anion substitution was observed by in situ SRPXD during the heating of a sample of $\mathrm{LiBH}_{4}-\mathrm{LiCl}(\mathrm{LiCl}$ $15 \mathrm{~mol} \%$ ) at $T>\sim 120{ }^{\circ} \mathrm{C}$ [47]. A typical anion substitution reaction is described in reaction scheme 3 ; that is, one solid, here $\mathrm{LiCl}$, is dissolved in another solid, $\mathrm{LiBH}_{4}$. Larger amounts of $\mathrm{LiCl}$ readily dissolve in solid hexagonal $h-\mathrm{LiBH}_{4}$.

$x \mathrm{LiCl}+(1-x) \mathrm{LiBH}_{4} \rightarrow \mathrm{Li}\left(\mathrm{BH}_{4}\right)_{1-x} \mathrm{Cl}_{x}$

The hexagonal solid solution, e.g. $h$ - $\mathrm{Li}\left(\mathrm{BH}_{4}\right)_{0.58} \mathrm{Cl}_{0.42}$, obtained by thermal treatment, is stable upon cooling to $R T$; however, slow segregation of $\mathrm{LiCl}$ occurs, and $o$ $\mathrm{Li}\left(\mathrm{BH}_{4}\right)_{0.91} \mathrm{Cl}_{0.09}$ is obtained after several months [47-49]. Bromide substitution clearly stabilizes the hexagonal structure of $\mathrm{LiBH}_{4}$ to $R T$ as a solid solution with the composition $h$ - $\mathrm{Li}\left(\mathrm{BH}_{4}\right)_{0.5} \mathrm{Br}_{0.5}$ [50]. Solid solutions of $\mathrm{Li}\left(\mathrm{BH}_{4}\right)_{1-x} \mathrm{I}_{x}$ have been obtained by reacting $\mathrm{LiBH}_{4}$ with $\alpha$-LiI $[51,52]$. The substitution process can be induced either by heat treatment at $T \sim 245^{\circ} \mathrm{C}$ or by mechanochemical treatment, and the solid solutions of $\mathrm{Li}\left(\mathrm{BH}_{4}\right)_{1-\mathrm{x}} \mathrm{I}_{\mathrm{x}}$ have a broader stability range compared to other halides (from $R T$ to the melting at $330{ }^{\circ} \mathrm{C}$ ) [51]. Dissolution of $10 \mathrm{~mol} \% \mathrm{NaCl}$ into $\mathrm{NaBH}_{4}$, forming $\mathrm{Na}\left(\mathrm{BH}_{4}\right)_{0.9} \mathrm{Cl}_{0.1}$, takes place during relatively mild mechanochemical treatment, and a higher degree of dissolution of $\mathrm{NaCl}$ in $\mathrm{NaBH}_{4}$ is obtained by heating (e.g. at $300{ }^{\circ} \mathrm{C}$ ), which enables full solubility in the system

Table 1 Ionic radius of halide anions, the $\mathrm{H}^{-}$and the $\mathrm{BH}_{4}{ }^{-}$anions [46]

\begin{tabular}{lllllll}
\hline Anion & $\mathrm{F}^{-}$ & $\mathrm{H}^{-}$ & $\mathrm{Cl}^{-}$ & $\mathrm{Br}^{-}$ & $\mathrm{BH}_{4}^{-}$ & $\mathrm{I}^{-}$ \\
\hline Radius $(\AA)$ & 1.33 & 1.40 & 1.81 & 1.96 & 2.05 & 2.20 \\
\hline
\end{tabular}


$\mathrm{NaBH}_{4}-\mathrm{NaCl}$. Ball milling of $\mathrm{NaBH}_{4}$ with $\mathrm{NaCl}$ results in the formation of a $\mathrm{Na}\left(\mathrm{BH}_{4}\right)_{1-x} \mathrm{Cl}_{x}$ solid solution that is stable at room temperature with $x$ in the whole range of 0 to 1 [53]. $\mathrm{Cl}$ substitution increases the stability [54-56]. Anion substitution in other systems has also been investigated, e.g. $\mathrm{Ca}\left(\mathrm{BH}_{4}\right)_{2}-\mathrm{CaX}_{2}$ with $\mathrm{X}=\mathrm{Cl}, \mathrm{Br}$ and I [57-59] and $\mathrm{Mg}\left(\mathrm{BH}_{4}\right)_{2}-\mathrm{MgX}_{2}(\mathrm{X}=\mathrm{Cl}$ and $\mathrm{Br})$ [60].

The smaller halide ion, $\mathrm{F}^{-}(1.33 \AA)$, has a similar size compared to the hydride ion, $\mathrm{H}^{-}(1.40 \AA)$, and their compounds share many chemical properties; for example, the ionic compounds are often found to be isostructural. This suggests that they may substitute for each other in both ionic and covalently bonded compounds. However, there is one significant difference, namely in electronegativity, which is 2.1 and 4.0 for hydrogen and fluorine, respectively. Therefore, fluorine substitution is expected to lead to significant thermodynamic destabilization. However, thermodynamic stabilization is also possible, as seen for $\mathrm{NaMgH}_{2} \mathrm{~F}$ [61]. The first complex hydride with fluorine substitution was prepared by hydrogenation of the system $\mathrm{NaF}-\mathrm{Al}$, which provided complex hydride $\mathrm{Na}_{3} \mathrm{AlH}_{6-\mathrm{x}} \mathrm{F}_{\mathrm{x}}$ $[62,63]$. Fluoride substitution in the $\mathrm{BH}_{4}{ }^{-}$complex anion, i.e. $\mathrm{H}^{-} \rightarrow \mathrm{F}^{-}$, is possible, e.g. the system $\mathrm{NaBH}_{4}-\mathrm{NaBF}_{4}$ provided $\mathrm{NaBH}_{2.1} \mathrm{~F}_{1.9}$, observed in a narrow temperature range of $200-215^{\circ} \mathrm{C}$ by SR-PXD [64]. Mechanochemical reactions between $\mathrm{KBH}_{4}$ and $\mathrm{KBF}_{4}$ result in the formation of $\mathrm{KBH}_{2.8} \mathrm{~F}_{1.2}$ and $\mathrm{KBH}_{1.8} \mathrm{~F}_{2.2}$, formed for the $3: 1$ and $1: 1$ mixtures, respectively [65]. Both of these phases, which are isostructural with $\mathrm{KBH}_{4}$, are stable at room temperature. The hydrogen release from $\mathrm{KBH}_{2.8} \mathrm{~F}_{1.2}$ takes place $433{ }^{\circ} \mathrm{C}$ lower than it does in pure $\mathrm{KBH}_{4}$ [63]. However, some of the obtained materials, specifically $\mathrm{NaB}\left(\mathrm{H}_{1-\mathrm{x}} \mathrm{F}_{\mathrm{x}}\right)_{4}$, appear to have relatively low thermal stability, and the released hydrogen may be contaminated with significant amounts of boron fluorides and/or borane gases and may lead to the formation of significant amounts of $M_{2} \mathrm{~B}_{12} \mathrm{H}_{12}$ [64-67].

\subsection{Eutectic melting complex hydrides}

Two or more complex hydrides may react and form a new compound, $\mathrm{MM}^{\prime}\left(\mathrm{BH}_{4}\right)_{\mathrm{x}}$, a solid solution [68, 69] or in some cases enable eutectic melting [70]. The system $\mathrm{xLiBH}_{4}+(1-x) \mathrm{Ca}\left(\mathrm{BH}_{4}\right)_{2}$ undergoes eutectic melting with a minimum temperature at ca. $200{ }^{\circ} \mathrm{C}$ in a relatively wide composition range $0.6<x<0.8$ [71]. The mixtures of $\mathrm{LiBH}_{4}-\mathrm{NaBH}_{4}, \quad \mathrm{LiBH}_{4}-\mathrm{KBH}_{4}, \quad \mathrm{LiBH}_{4}-\mathrm{Mg}\left(\mathrm{BH}_{4}\right)_{2}$, $\mathrm{LiBH}_{4}-\mathrm{Ca}\left(\mathrm{BH}_{4}\right)_{2}, \mathrm{LiBH}_{4}-\mathrm{Mn}\left(\mathrm{BH}_{4}\right)_{2}, \mathrm{NaBH}_{4}-\mathrm{KBH}_{4}$ and $\mathrm{LiBH}_{4}-\mathrm{NaBH}_{4}-\mathrm{KBH}_{4}$ all displayed melting behaviour below that of the monometallic phases (up to $167^{\circ} \mathrm{C}$ lower) [70-74]. Generally, each system can behave differently with respect to their physical behaviours upon melting. The molten phases can exhibit a range of physical changes including colour changes, bubbling and in some cases frothing, or even liquid-solid phase transitions during hydrogen release [70]. The mixture with the lowest melting point is $0.725 \mathrm{LiBH}_{4}-0.275 \mathrm{KBH}_{4}, T_{\mathrm{m}}=105{ }^{\circ} \mathrm{C}$ [74].

\subsection{Trends in structures}

Interestingly, the crystal structures of the majority of novel metal borohydrides resemble those of various oxides, as illustrated by the structures of $\alpha / \alpha^{\prime}-, \beta$ - and $\gamma-\mathrm{Ca}\left(\mathrm{BH}_{4}\right)_{2}$, which are isomorphous to the $\mathrm{TiO}_{2}$ polymorphs rutile, anatase and brookite, respectively [75]. Magnesium borohydrides are structurally similar to $\mathrm{SiO}_{2}$ compounds; for example, $\gamma-\mathrm{Mg}\left(\mathrm{BH}_{4}\right)_{2}$ is isomorphous to a theoretically predicted zeolite-type polymorph of $\mathrm{SiO}_{2}$, and $\delta-\mathrm{Mg}\left(\mathrm{BH}_{4}\right)_{2}$ has a structure consisting of two interpenetrated cristobalite-type $\mathrm{Mg}\left(\mathrm{BH}_{4}\right)_{2}$ frameworks (i.e. polymorph of $\mathrm{SiO}_{2}$ ) [28, 76]. The explanation for this structural analogy between the structures of borohydrides and those of oxides is possibly the fact that $\mathrm{BH}_{4}^{-}$and $\mathrm{O}^{2-}$ are isoelectronic. Monometallic borohydrides of the least electronegative metals, e.g. Na, K, Rb and $\mathrm{Cs}$, are often considered as ionic and have high melting points and stabilities. More electronegative metals may form molecular, covalent and volatile compounds, e.g. $\mathrm{Al}\left(\mathrm{BH}_{4}\right)_{3}, \mathrm{Zr}\left(\mathrm{BH}_{4}\right)_{4}$ and $\mathrm{Hf}\left(\mathrm{BH}_{4}\right)_{4}$ [77-80]. Between these extremes, numerous metal borohydrides with framework structures, pronounced directionality in the bonding and clearly some degree of covalence are found, e.g. $\mathrm{Mg}\left(\mathrm{BH}_{4}\right)_{2}$ and $\mathrm{Mn}\left(\mathrm{BH}_{4}\right)_{2}$ [27, 28]. Bi- and tri-metallic borohydrides often consist of complex metal borohydride anions counterbalanced by an alkali cation. In all the structures, the more electronegative metal constitutes the central atom in the complex anions by coordination to a number of borohydride units. In contrast, the majority of metal borohydride halides crystallize with structures similar to metal halides of the same metal and are often isostructural to high temperature polymorphs [68, 69].

\subsection{New properties of metal borohydrides-towards multi-functionality}

The new metal borohydrides discovered during the past decade reveal an extreme diversity in structure, composition and properties, with progress towards the rational design of new materials with tailored properties, as exemplified in the following.

A new series of mixed-cation, mixed-anion borohydride chlorides based on rare-earth elements, $\mathrm{Li} M\left(\mathrm{BH}_{4}\right)_{3} \mathrm{Cl}$, $M=\mathrm{La}$, $\mathrm{Gd}$ and $\mathrm{Ce}$, was discovered containing isolated tetranuclear anionic clusters of $\left[\mathrm{Ce}_{4} \mathrm{Cl}_{4}\left(\mathrm{BH}_{4}\right)_{12}\right]^{4-}$ chargebalanced by $\mathrm{Li}^{+}$cations $[38,40,41]$. The $\mathrm{Li}^{+}$ions are disordered and occupy two-thirds of the available positions and are found to be a new series of fast Li-ion conductors for metal borohydrides, as was originally reported in $h$ - 
$\mathrm{LiBH}_{4}$ [81] Structural investigation using theoretical DFT methods suggests that the structures are stabilized by higher entropy rather than lower energy [40]. Solid-state NMR spectroscopy reveals a "paddle wheel" mechanism for the ion conductivity [42]. Furthermore, anion substitution in lithium borohydride significantly improves the lithium ion conductivity for $\mathrm{LiBH}_{4}$ because the hexagonal structure may be stabilized at RT $[82,83]$. The high Li-ion conductivity of $h$ - $\mathrm{LiBH}_{4}-\mathrm{Li} X, X=\mathrm{Cl}, \mathrm{Br}$, I, may also be due to the dynamics of the $\mathrm{BH}_{4}$ unit in the solid structures $[52,84]$.

The polymorph $\gamma-M\left(\mathrm{BH}_{4}\right)_{2}, M=\mathrm{Mg}$ or $\mathrm{Mn}$, has a 3D network of interpenetrated channels with pore sizes in the range of $6-8 \AA$, i.e. $30 \%$ "empty space," and is the first metal hydrides with a large permanent porosity [27, 28]. These compounds may also reversibly adsorb smaller molecules, e.g. $\mathrm{H}_{2}, \mathrm{~N}_{2}$ or $\mathrm{CH}_{2} \mathrm{Cl}_{2}$. Rietveld refinements revealed storage capacities of $\gamma-\mathrm{Mg}\left(\mathrm{BH}_{4}\right)_{2} \cdot 0.80 \mathrm{H}_{2}$ at $p\left(\mathrm{H}_{2}\right)=105$ bar, which corresponds to a total of $17.4 \mathrm{wt} \%$ $\mathrm{H}_{2}[27,28]$.

A series of 30 new perovskite, $A B X_{3}$, metal borohydrides were recently discovered, built from, e.g. $A=\mathrm{K}^{+}$, $\mathrm{Rb}^{+}, \mathrm{Cs}^{+}, \mathrm{NH}_{4}^{+}, \mathrm{CH}_{3} \mathrm{NH}_{3}{ }^{+} ; B=\mathrm{Li}^{+}, \mathrm{Mg}^{2+}, \mathrm{Ca}^{2+}, \mathrm{Sr}^{2+}$, $\mathrm{Sn}^{2+}, \mathrm{Pb}^{2+}, \mathrm{Mn}^{2+}, \mathrm{Y}^{3+}, \mathrm{Ce}^{3+}, \mathrm{Eu}^{2+}, \mathrm{Yb}^{2+}, \mathrm{Gd}^{3+}$ and $X=\mathrm{BH}_{4}^{-}, \mathrm{Cl}^{-}, \mathrm{Br}^{-}, \mathrm{I}^{-}$[85]. Structural dynamics on the anion site are systematically introduced to the perovskite structure type, and anion substitution, where $\mathrm{BH}_{4}{ }^{-}$is partially replaced by the heavier halides, $\mathrm{Cl}^{-}, \mathrm{Br}^{-}$or $\mathrm{I}^{-}$, readily occurs, contributing to a vast structural flexibility and compositional diversity. These new compounds may, in addition to hydrogen storage properties, also have optical and magnetic properties.

The novel compound, ammonium borohydride perovskite $\mathrm{NH}_{4} \mathrm{Ca}\left(\mathrm{BH}_{4}\right)_{3}\left(\rho_{\mathrm{m}}=15.7 \mathrm{wt} \% \mathrm{H}_{2}\right)$, can be considered the first successful stabilization of the metastable compound $\mathrm{NH}_{4} \mathrm{BH}_{4}$ with a great hydrogen content of $\rho_{\mathrm{m}}=24.5 \mathrm{wt} \% \mathrm{H}_{2}$ [86]. The tailoring of hydrogen storage properties by ammonia or amide has become an established approach [6, 35, 36, 87], but ammonium $\mathrm{NH}_{4}{ }^{+}$has so far not been considered.

A wide range of novel rare-earth metal borohydrides have also been described recently, as presented in Table 2, which reveals new trends in crystal chemistry and properties. The thermal decomposition behaviours are also reported in this table [39] (Fig. 1).

\section{Thermodynamics of complex hydrides}

\subsection{Thermodynamic quantities}

In order to understand the stability of complex hydrides, a full knowledge of thermodynamics is necessary. So, the
Gibbs free energy $(G)$ of the compounds has to be described as a function of temperature $(T)$ and pressure $(P)$. If a variable stoichiometry is observed in the complex hydride, the dependence from the composition $(X)$ needs to be known. The temperature dependence can be reached if the specific heat at constant pressure $(C P)$ is determined. From that, the enthalpy $(H)$ and entropy $(S)$ can be easily calculated by integration, and, as a consequence, $G$ can be obtained. In order to define the standard thermodynamic properties of the compound, $C p$ values should be available starting from a low temperature (close to $0 \mathrm{~K}$ ) up to room temperature $(300 \mathrm{~K})$. Pressure dependence of $G$ is usually rather limited for condensed phases (i.e. solid and liquid), and, for gaseous phases, it can be easily estimated from partial pressure values. Dealing with phase transformations and scaffold interaction in complex hydrides, surface energy and interfacial energy should be known as well, possibly as a function of $T$ and $P$. In this case, energy values are affected by the environmental conditions, i.e. gas or solid phases in equilibrium with the complex hydride.

When a hydrogen sorption reaction is established, $G$ has to be known for all involved reagents and products, and a clear description of the reaction paths is mandatory in order to define the relative stability of complex hydrides. So, the knowledge of the thermodynamic properties of complex hydrides is necessary for defining the relative stability of different phases and for understanding hydrogen sorption reactions. Finally, it is worth noting that thermodynamic properties also play a key role in driving the kinetics of hydrogen sorption reactions, e.g. defining the driving force for nucleation.

\subsection{Experiments}

Thermodynamic quantities for complex hydrides are generally obtained by experiments. Among them, techniques involving equilibrium between solid and gas phases are of primary importance. Van't Hoff plots are widely used to obtain values for $H$ and $S$. Because these values are obtained from the relationship between equilibrium hydrogen pressure and temperature, the occurrence of an uncompleted sorption reaction can also be accepted in order to determine reliable data. It is to be stressed that the determination of thermodynamic properties via Van't Hoff plots needs a high level of accuracy and reproducibility of experimental data $[88,89]$. As a consequence, measurements should be performed in a large temperature range, even if this approach forces $\mathrm{H}$ and $\mathrm{S}$ to be constant in the investigated experimental conditions. In addition, it is fundamental to reach real equilibrium conditions during the measurements, as evidenced by the occurrence of flat pressure plateaux. Knudsen's cell technique [90] has 
Table 2 Overview of rare-earth borohydride crystal structures

\begin{tabular}{lccccccccccccccc}
\hline & $\mathrm{La}$ & $\mathrm{Ce}$ & $\mathrm{Pr}$ & $\mathrm{Nd}$ & $\mathrm{Pm}$ & $\mathrm{Sm}$ & $\mathrm{Eu}$ & $\mathrm{Gd}$ & $\mathrm{Tb}$ & $\mathrm{Dy}$ & $\mathrm{Ho}$ & $\mathrm{Er}$ & $\mathrm{Tm}$ & $\mathrm{Yb}$ & $\mathrm{Lu}$ \\
\hline $\operatorname{LiRE}\left(\mathrm{BH}_{4}\right)_{3} \mathrm{Cl}$ & $\mathrm{X}$ & $\mathrm{X}$ & $\mathrm{X}$ & $\mathrm{X}$ & & $\mathrm{X}$ & & $\mathrm{X}$ & & & & & & & \\
$\alpha-\mathrm{RE}\left(\mathrm{BH}_{4}\right)_{3}$ & & & & & & $\mathrm{X}$ & & $\mathrm{X}$ & $\mathrm{X}$ & $\mathrm{X}$ & & $\mathrm{X}$ & $\mathrm{X}$ & $\mathrm{X}$ & \\
$\beta-\mathrm{RE}\left(\mathrm{BH}_{4}\right)_{3}$ & & & & & & $\mathrm{X}$ & & & & & & $\mathrm{X}$ & & $\mathrm{X}$ & \\
$\operatorname{LiRE}\left(\mathrm{BH}_{4}\right)_{4}$ & & & & & & & & & & & & & & $\mathrm{X}$ & $\mathrm{X}$ \\
$\operatorname{RE}\left(\mathrm{BH}_{4}\right)_{3}$ & & & & & & $\mathrm{X}$ & & & & & & & & $\mathrm{X}$ & \\
\hline
\end{tabular}

Fig. 1 Structure types and motives observed among different lanthanide borohydrides: a distorted $\mathrm{RE}^{3+} \mathrm{Cl}$ heterocubane; b distorted rhenium trioxide structure type; c regular rhenium trioxide structure type; d $\mathrm{LiSc}\left(\mathrm{BH}_{4}\right)_{4}$-related structure. Rare-earth atoms are black, chloride atoms are green and lithium atoms are blue, and $\mathrm{BH}_{4}$ groups are shown as red polyhedra. Hydrogen atoms have been omitted for clarity. Note that the structure of $\beta$ $\mathrm{RE}\left(\mathrm{BH}_{4}\right)_{3}$ in $(\mathbf{c})$ shows disordered $\mathrm{BH}_{4}$ units (visualized by red cubes) when analysed by $\mathrm{X}$-ray diffraction. The $\mathrm{BH}_{4}$ groups appear fully ordered when viewed by neutron diffraction

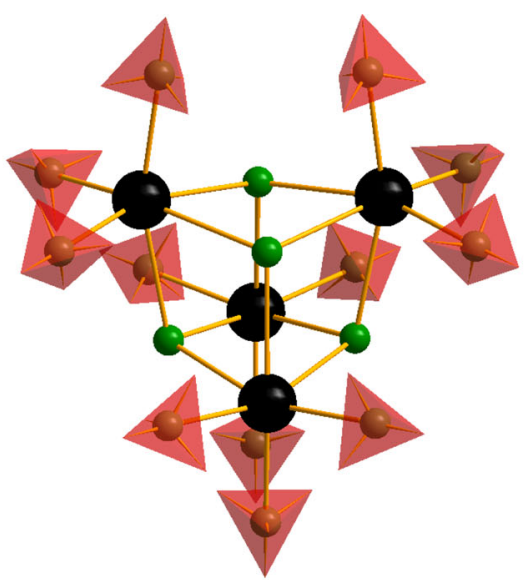

(a) $\mathrm{LiRE}\left(\mathrm{BH}_{4}\right)_{3} \mathrm{Cl} \quad \mathrm{RE}=\mathrm{La}, \mathrm{Ce}, \mathrm{Pr}, \mathrm{Nd}, \mathrm{Sm}$, $\mathrm{Gd}$

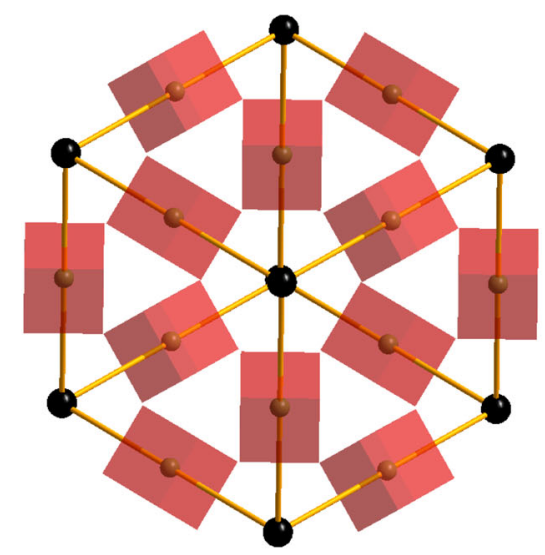

(c) $\beta-R E\left(\mathrm{BH}_{4}\right)_{3} \quad R E=\mathrm{Sm}, \mathrm{Er}, \mathrm{Yb}$

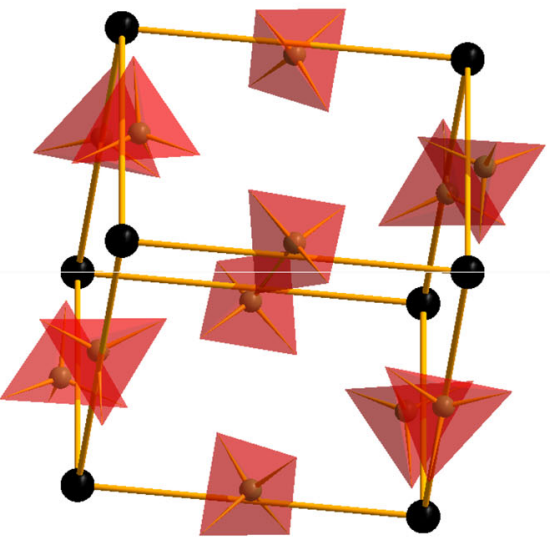

(b) $\alpha-R E\left(\mathrm{BH}_{4}\right)_{3} \quad R E=\mathrm{Sm}, \mathrm{Gd}, \mathrm{Tb}, \mathrm{Dy}, \mathrm{Er}$; $\mathrm{Tm}, \mathrm{Yb}$

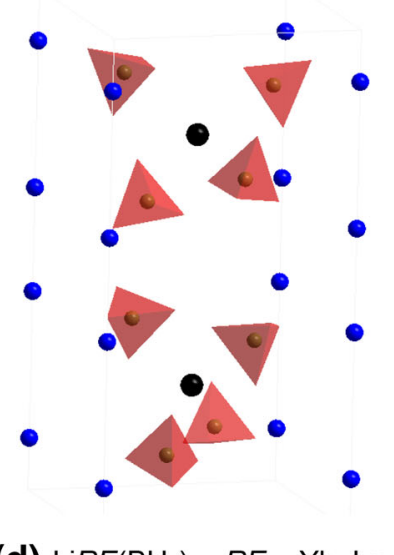

(d) $\operatorname{LiRE}\left(\mathrm{BH}_{4}\right)_{4} \quad R E=\mathrm{Yb}, \mathrm{Lu}$ seldom been used for the determination of thermodynamic properties in complex hydrides. As an example, the thermodynamic properties of $\mathrm{Mg}\left(\mathrm{BH}_{4}\right)_{2}$ have been recently obtained by this approach [91].

Calorimetry is the foremost technique to obtain thermodynamic information for complex hydrides. DSC is also widely used [92], thanks to recent developments of equipment, able to provide reliable data under a hydrogen pressure up to 200 bar. Calorimetric techniques are generally used to study phase transformations, allowing the determination of the temperature $\left(T_{\mathrm{tr}}\right)$, enthalpy $\left(\Delta H_{\mathrm{tr}}\right)$ and, from them, entropy $\left(\Delta S_{\text {tr }}\right)$ of phase transformations. From a simple integration of the calorimetric signal obtained in isothermal conditions, phase fraction can be determined as a function of time, allowing the determination of kinetic information (e.g. activation energy and pre-exponential factor). $C p$ measurements have been performed for complex hydrides by differential scanning calorimeter in various temperature ranges [93]. Recently, low $T$ measurements of $C p$ have also been obtained by calorimetric techniques, allowing the determination of fundamental thermodynamic properties for various systems [87]. 


\subsection{Modelling}

An estimation of the energy of formation of a complex hydride can be obtained through ab initio modelling [94]. On the basis of the density functional theory (DFT), ab initio calculations of the ground state energy, energy gradient, electronic wave function and properties (electronic, vibrational, thermodynamic and elastic) of periodic systems can be obtained. In fact, ground state energy calculations provide basic insight into the structural stability and electronic structure modification of compounds. After suitable approximations, calculated values for the enthalpy of formation ( $\left.\Delta H_{\text {for }}\right)$ for complex hydrides can be obtained. As an example, the ab initio modelling of borohydrides has been recently carried out [34]. In order to perform ab initio calculations, the crystal structures of the complex hydride need to be known, even if strategies to predict them have been recently suggested [95].

A full picture of the thermodynamic properties of a system can be obtained by using the CALPHAD approach [96], where the analytical description of the temperature dependence of free energy, enthalpy, entropy and specific heat is given by parametric expressions. Parameters can be obtained with a least square procedure, starting from experimental values of existing phase diagrams and thermodynamic data. $G$ functions as a function of $T$ for solution phases are often described in terms of Redlich-Kister polynomials, whereas for compounds, they are described on the basis of an enthalpy and entropy of formation. The base of the CALPHAD method is the availability of thermochemical data related to the investigated systems. For some complex hydrides, they are collected from suitable thermodynamic databases [97]. In the absence of experimental information, the output of DFT calculations can be used. CALPHAD assessments of various hydride systems have been carried out in recent years [98]. The suggested approach, including a combination of CALPHAD and ab initio modelling, has been recently applied to complex hydrides. As an example, equilibrium pressuretemperature $(P-T)$ phase diagrams for $\mathrm{NaBH}_{4}$ [99], $\mathrm{LiBH}_{4}$ [100] and $\mathrm{Mg}\left(\mathrm{BH}_{4}\right)_{2}$ [101] are shown in Fig. 2. If, for kinetic reasons, stable phases cannot be formed during hydrogen desorption, metastable phase diagrams can be easily calculated in order to explain observed experimental results [99].

\subsection{Use of thermodynamics for advanced strategies}

Combinations of materials or reactions can be used to tune the overall thermodynamics of a given system to achieve more favourable products or reaction temperatures. For example, the addition of $\mathrm{Si}$ (or $\mathrm{Ge}, \mathrm{Sn}$ ) metal to $\mathrm{LiH}$ or $\mathrm{MgH}_{2}$ results in the formation of relatively stable group IV alloys upon dehydrogenation, effectively destabilizing the metal hydride and increasing the equilibrium hydrogen pressure at a given temperature [102, 103]. Similarly, adding $\mathrm{MgH}_{2}$ to $\mathrm{LiBH}_{4}$ lowers the dehydrogenation enthalpy of the borohydride through the formation of $\mathrm{MgB}_{2}$ [104]. The thermodynamics of the $\mathrm{H}_{2}$ release from ammonia borane can be modified by substitution of a proton on the nitrogen; for example, $\mathrm{H}-\mathrm{NH}_{2}-\mathrm{BH}_{3}+\mathrm{MH} \rightarrow \mathrm{MNH}_{2}$ $\mathrm{BH}_{3}+\mathrm{H}_{2}$ decreases the reaction exothermicity from ca. $-20 \mathrm{~kJ} / \mathrm{mol}$ to ca. $-4 \mathrm{~kJ} / \mathrm{mol}$ [87, 105]. Alternatively, substitution of a methylene group on nitrogen, i.e. $\mathrm{BH}_{3} \mathrm{NH}_{2}$ $\mathrm{CH}_{2} \mathrm{CH}_{2} \mathrm{BH}_{3}$, resulted in a decrease in reaction enthalpy and a change in the mechanism of $\mathrm{H}_{2}$ release that made the ammonia borane complex more stable at $80{ }^{\circ} \mathrm{C}$ and less stable at $100{ }^{\circ} \mathrm{C}$ [106]. An advantage of decreasing the reaction enthalpy of the $\mathrm{H}_{2}$ release in the chemical hydrogen storage materials is to reduce the external cooling requirements to prevent thermal runaway.

Another advanced strategy is to use the heat generated in an exothermic reaction to drive a second endothermic reaction [107], an approach also employed in the autothermal reforming of hydrocarbons [108]. Wechsler et al. proposed a mixture of an exothermic and endothermic hydrogen storage material to make a single thermoneutral reaction. Cooper describes a process with two separate reactors that can be thermally coupled. The heat from an exothermic reaction is transferred to the dehydrogenation reactor to drive this endothermic process. This concept of coupling exothermic and endothermic $\mathrm{H}_{2}$ release pathways could also be used to release more $\mathrm{H}_{2}$ from the cyclic CBN systems described by Liu et al. [109, 110]. In the 1,2 BN cyclohexane compounds [111], thermal release of $\mathrm{H}_{2}$ from the $\mathrm{BN}$ portion of the molecule is exothermic and may be coupled with the catalytic endothermic release of $\mathrm{H}_{2}$ from the $\mathrm{C}$ atoms in the ring. In the scheme below, the exothermic reaction yields $4.7 \mathrm{wt} \% \mathrm{H}_{2}$ and a significant amount of heat, which can be used to drive hydrogen off the carbon backbone to yield an additional $4.7 \mathrm{wt} \% \mathrm{H}_{2}$, for a total of $>9 \mathrm{wt} \% \mathrm{H}_{2}$ (Fig. 3).

Work is in progress to determine the optimum balance of rates and enthalpies for coupling endothermic and exothermic reactions in the CBN materials [112].

\section{Stability of borohydrides/alanates}

The stability of complex hydrides, i.e. alanates and borohydrides, is given by the enthalpy and entropy difference between the hydride and the first stable desorption product, which is in most cases different from the pure elements. Therefore, we have to distinguish between the stability and the enthalpy of the formation of a specific complex hydride. While the enthalpy of the formation of a metallic 

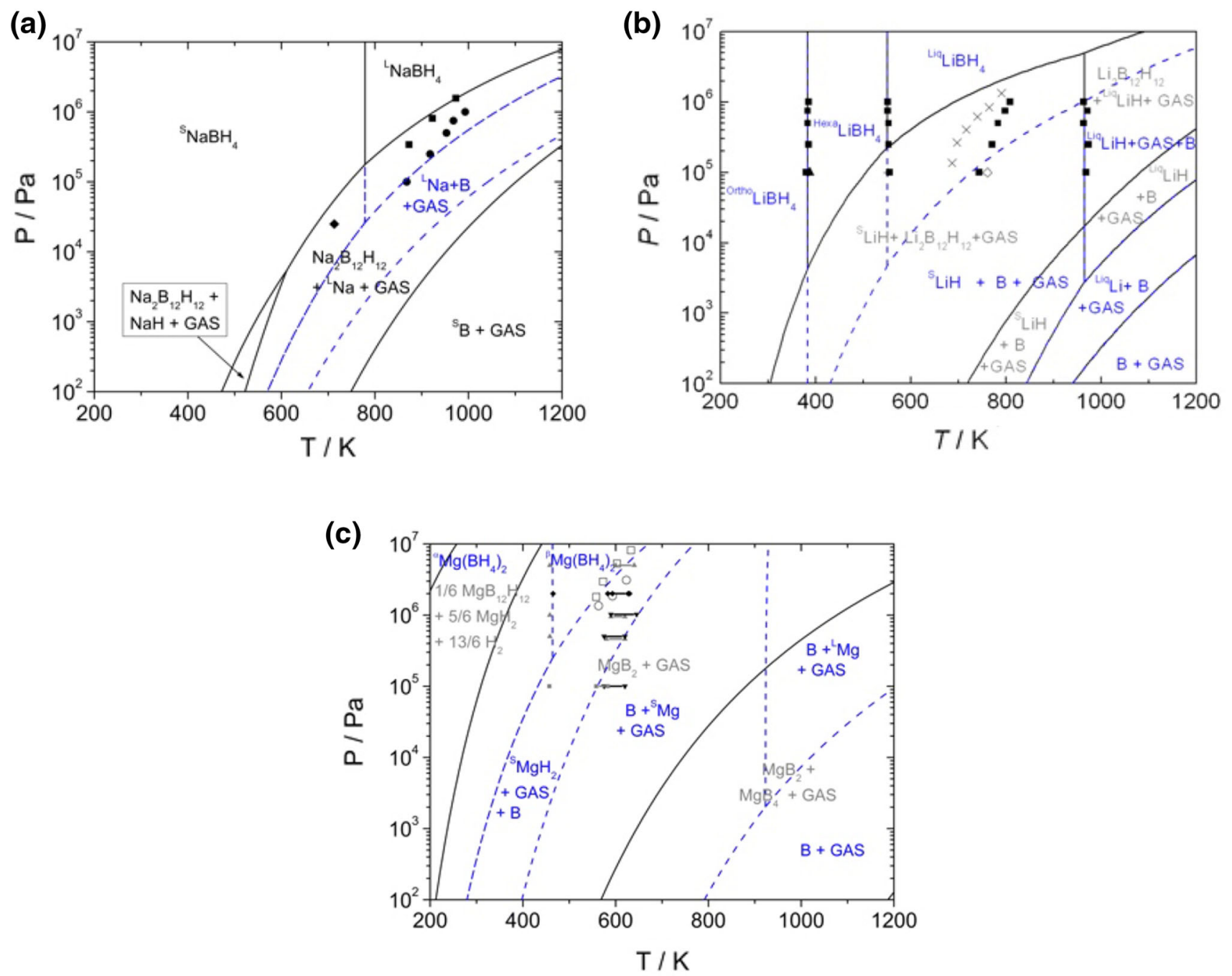

Fig. 2 P-T phase diagram for a $\mathrm{NaBH}_{4}$ [99], b $\mathrm{LiBH}_{4}$ [100] and $\mathbf{c} \mathrm{Mg}(\mathrm{BH} 4)_{2}$ [101]. Lines calculated by the CALPHAD method (continuous: stable; dashed: metastable). Points experiments (see references for details)

Fig. 3 First step of $\mathrm{H}_{2}$ release from $\mathrm{NH}_{2}-\mathrm{BH}_{2}$ is exothermic; second step of $\mathrm{H}_{2}$ release from $\mathrm{CH}_{2} \mathrm{CH}_{2}$ is endothermic. Using the heat released in step 1 to warm the reactor will require less external addition of heat, enhancing the overall efficiency of $\mathrm{H}_{2}$ release
(1) Exothermic

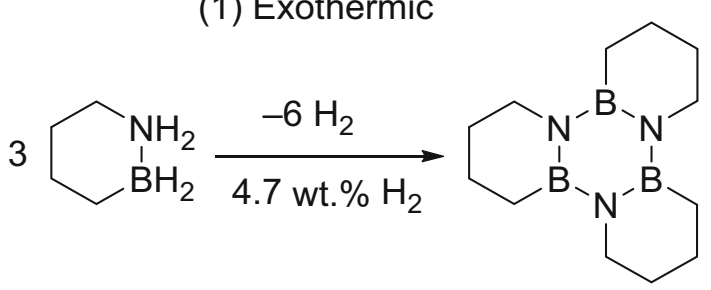

(2) Endothermic

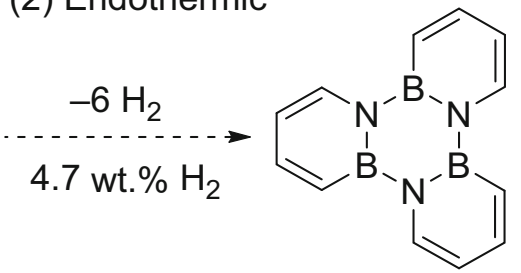

total 9.4 wt. $\% \mathrm{H}_{2}$ hydride is determined by the local electron density on the interstitial site where hydrogen is hosted $[113,114]$ and the metal structure undergoes only minor changes upon hydrogen absorption, a complex hydride is not an intercalation compound and forms multiple phases upon hydrogen desorption. The stability of an $\left[\mathrm{AlH}_{4}\right]^{-}$or a
$\left[\mathrm{BH}_{4}\right]^{-}$is determined by the localization of the electron on the $\mathrm{Al}$ and $\mathrm{B}[115,116]$. The enthalpy of formation of a series of borohydrides was computed by DFT calculation, and a linear correlation between the enthalpy of formation and the electronegativity of the cation-forming element was found [117]: 
$\Delta H\left[\mathrm{~kJ} / \mathrm{mol} \mathrm{BH}_{4}\right]=247.4 \cdot E N-421.2$,

where $E N$ is the Pauling electronegativity of $M$ in $M\left(\mathrm{BH}_{4}\right)_{\mathrm{x}}$. A similar equation can be derived for alanates:

$\Delta H\left[\mathrm{~kJ} / \mathrm{mol} \mathrm{AlH} \mathrm{H}_{4}\right]=308 \cdot E N-411$.

Therefore, by applying the Pauling electronegativity of $\mathrm{B}$ (2.04) and $\mathrm{Al}$ (1.61), a general equation for the enthalpy of formation is derived (Fig. 4):

$$
\begin{aligned}
\Delta H\left[\mathrm{~kJ} / \mathrm{mol} \mathrm{Z} \mathrm{ZH}_{4}\right]= & 143 \cdot E N(\mathrm{~B}, \mathrm{Al}) \cdot E N-224 \\
& \cdot E N(\mathrm{~B}, \mathrm{Al}) .
\end{aligned}
$$

Upon hydrogen desorption, the alanates and borohydrides form either an elemental hydride from the cation and hydrogen or the element in case the elemental hydride is not stable at the desorbing conditions. The use of additives and catalysts might change the described picture, resulting in the formation of a transient species [122, 123]. The main difference between the alanates and borohydrides is the formation of the hexahydride in the case of the alanates (this does not happen for borohydrides [124]). This introduces an additional level (intermediate) during the desorption reaction and, therefore, divides the desorption enthalpy into two parts. The general relationship between the enthalpy of formation and the enthalpy of desorption is $\Delta H_{f}^{0}=\Delta H_{m}+\Delta H_{\mathrm{des}}+\Delta H_{\mathrm{HM}}$, where $\Delta H_{\mathrm{des}}$ has two parts $\left(\Delta H_{\mathrm{des}}=\Delta H_{\mathrm{des}}^{l}+\Delta H_{\mathrm{des}}^{2}\right)$ in the case of the formation of the hexahydride. Of course, if the desorption occurs from the solid, the melting enthalpy is zero in the equation. $\Delta H_{\mathrm{HM}}$ is the enthalpy of formation of the elemental hydride and is given by the Pauling equation $\Delta H_{\mathrm{HM}}$ $[\mathrm{kJ} / \mathrm{mol}]=\Delta H_{\mathrm{MM}}[\mathrm{kJ} / \mathrm{mol}]+194\left(\mathrm{EN}_{\mathrm{M}}-\mathrm{EN}_{\mathrm{H}}\right)^{2}$. If no elemental hydride is formed, $\Delta H_{\mathrm{HM}}$ is zero in the equation. The melting enthalpy is in the order of $\Delta \mathrm{Hm}=7 \mathrm{~kJ} / \mathrm{mol}$ [125]. The entropy change in the hydrogen desorption from

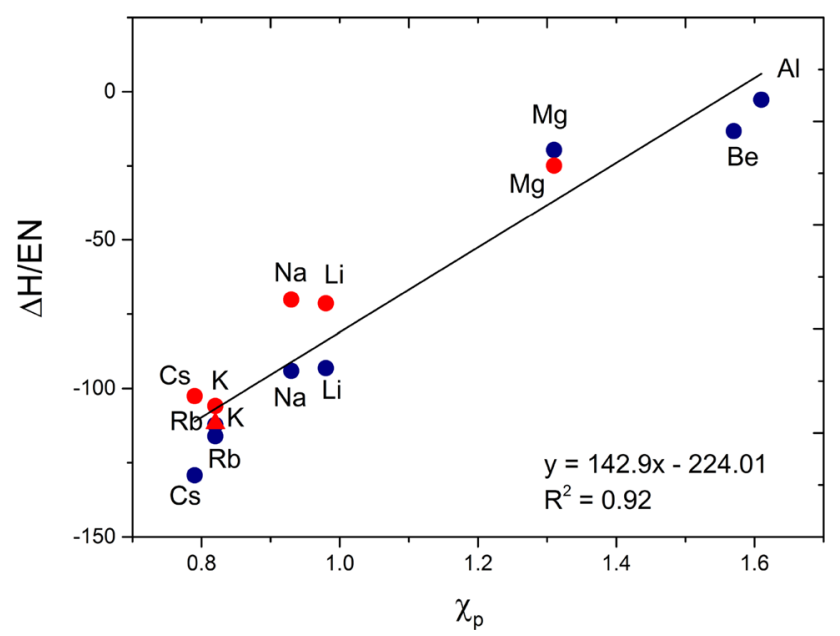

Fig. 4 Enthalpy of formation for lithium [118, 119], sodium [120] and potassium [118, 121] alanates (red) and borohydrides (blue) a complex borohydride is $\Delta S=\Delta S\left(\mathrm{H}_{2}\right)+\Delta S(M \mathrm{H})+$ $\Delta S(\mathrm{~B})-\Delta S\left(\mathrm{MBH}_{4}\right)$ and is larger than the standard entropy of hydrogen $\left(S^{O}=130 \mathrm{~J} / \mathrm{mol} \mathrm{K}\right)$, because $\Delta S(M \mathrm{H})+\Delta S(\mathrm{~B})>\Delta S\left(M \mathrm{BH}_{4}\right)$.

\section{Nanoconfined complex metal hydrides}

Nanosizing and scaffolding have emerged as an important strategy to control the kinetics, reversibility and equilibrium pressure for hydrogen storage in light metal hydride systems. For a detailed background, the reader is referred to some excellent reviews that have appeared recently [126-130]. In this section, we discuss a few highlights from the past 5 years (2010-2015).

\subsection{Strategies to prepare nanoconfined materials}

Complex metal hydrides can be confined into a matrix by solution impregnation (for instance, using $\mathrm{NaAlH}_{4}$ in tetrahydrofurane) followed by heat treatment to remove the solvent [131]. Alternatively, melt infiltration can be applied for complex metal hydrides with low melting points (e.g. $\mathrm{NaAlH}_{4} 181{ }^{\circ} \mathrm{C}$ and $\mathrm{LiBH}_{4} 280{ }^{\circ} \mathrm{C}$ ) [132, 133], despite a predicted weak interaction with carbon scaffolds [134]. Pore-confined reaction has recently been developed as an interesting alternative. One of the earliest reports is on $\mathrm{Mg}_{2} \mathrm{NiH}_{4}$, formed by the deposition of $\mathrm{Mg}$ into the pores of a carbon scaffold that already contained $\mathrm{Ni}$ nanoparticles [135]. The resulting $\sim 4 \mathrm{~nm} \quad \mathrm{Mg}_{2} \mathrm{Ni}$ and $\mathrm{Mg}_{2} \mathrm{NiH}_{4}$ nanoparticles were very stable upon cycling, with sorption being achieved within $5 \mathrm{~min}$ at $210^{\circ} \mathrm{C}$ [136]. Magnesium boron hydrides were prepared by the pre-deposition of $\mathrm{Mg}$ nanoparticles, followed by an exclusively pore-confined reaction (because of the high reactivity of the pore-confined nanoparticles) with diborane [137, 138]. Nanoconfined $\mathrm{MgB}_{12} \mathrm{H}_{12}$ was the major phase, but $\mathrm{Mg}\left(\mathrm{BH}_{4}\right)_{2}$ and a range of other magnesium boron hydrides can also be formed by the addition of $\mathrm{Ni}$ and by tuning the synthesis conditions [138]

In addition, two or more hydrides can be co-confined. For instance, a carbon aerogel-containing $\mathrm{MgH}_{2}$ nanoparticles was subsequently melt infiltrated with $\mathrm{LiBH}_{4}$ [139]. Simultaneous desorption of hydrogen and formation of $\mathrm{MgB}_{2}$ was observed, but only if a hydrogen back pressure of 5 bar was applied [140] $\mathrm{LiBH}_{4}$ and $\mathrm{Ca}\left(\mathrm{BH}_{4}\right)_{2}$ from a eutectic mixture, melting at $200{ }^{\circ} \mathrm{C}$. Infiltration into mesoporous carbon materials has been achieved, and hydrogen was released at temperatures clearly lower than for any of the separate complex metal hydrides (Fig. 5) [141, 142]. Other recently reported combinations include $\mathrm{Mg}_{2} \mathrm{NiH}_{4}-\mathrm{LiBH}_{4}$ [143], $\mathrm{LiBH}_{4}-\mathrm{MgH}_{2}-\mathrm{TiCl} 4$ [144] and $\mathrm{LiBH}_{4}-\mathrm{LiAlH}_{4}$ [145]. In all cases, hydrogen release 
Fig. 5 Left frame scanning electron micrograph of a carbon aerogel, a typical host material; right frame hydrogen desorption, cycles $1-3$ for $0.7 \mathrm{LiBH}_{4}-0.3 \mathrm{Ca}\left(\mathrm{BH}_{4}\right)_{2}$ infiltrated in carbon aerogel [142]

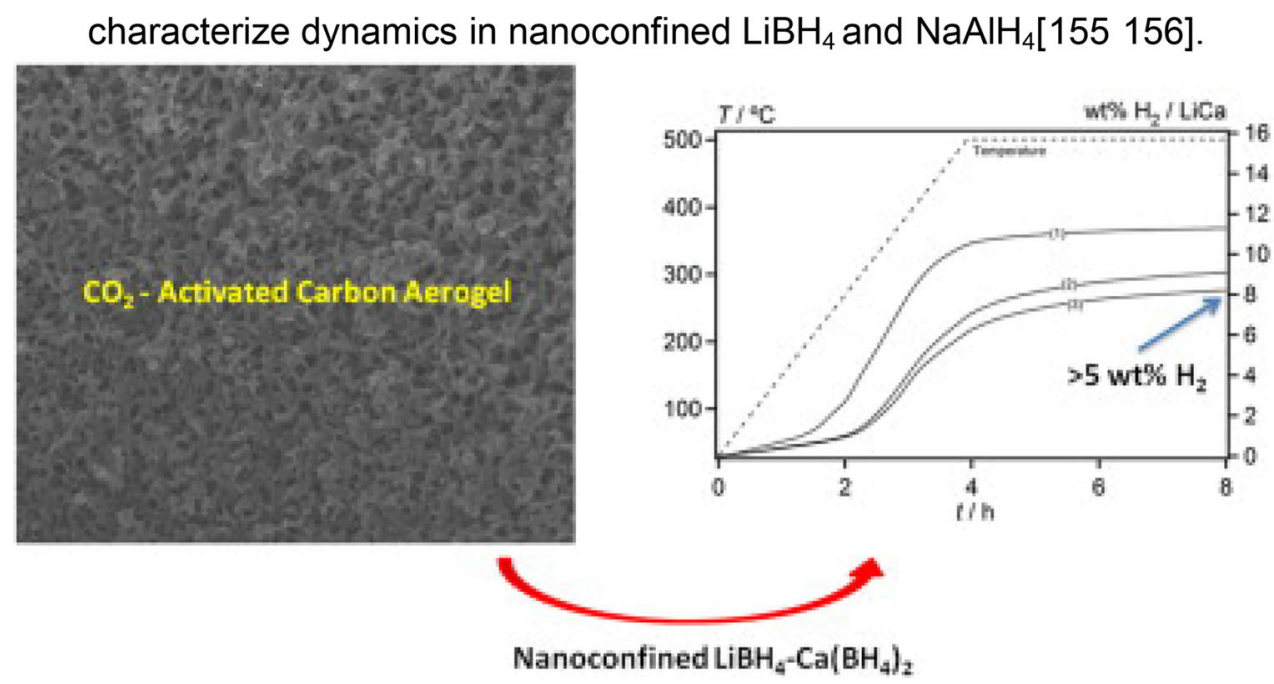

temperatures are lowered significantly, but the nanoconfinement is not sufficient to fully prevent capacity fading upon cycling.

Characterization of the nanoconfined complex metal hydrides is a challenge; they usually lack long-range crystallinity (hence invalidating diffraction techniques), the carbon matrix is unfavourable for optical spectroscopy, and electron microscopy is only possible in exceptional cases [146]. Small angle scattering can provide information on the particle size distribution as well as on the roughness of the particles and scaffolds [147, 148]. Solid-state NMR cannot serve to give only quantitative information of the phases present in the pores, but also valuable information on atomic mobilities [149-151]. Also, quasi-elastic neutron scattering is increasingly used to characterize dynamics in nanoconfined $\mathrm{LiBH}_{4}$ and $\mathrm{NaAlH}_{4}[152,153]$.

\subsection{Combining nanoconfinement with catalysis}

Porous carbon materials are also in wide use as catalyst supports, and hence, a logical idea was to explore a combination of catalyst nanoparticles with nanoconfined metal hydrides, achieving an intimate contact between the two. An early example is a $\mathrm{Ni} @ \mathrm{C}$ catalyst melt infiltrated with $\mathrm{LiBH}_{4}$. Figure 6 shows the synergistic effect of nanoconfinement and catalyst addition, with a $100-150{ }^{\circ} \mathrm{C}$ decrease in dehydrogenation temperature compared to bulk $\mathrm{LiBH}_{4}$, and a rapid rehydrogenation under mild conditions $\left(320^{\circ} \mathrm{C}\right.$ and 40 bar $\mathrm{H}_{2}$ ) [154]. A more detailed mechanistic study that it is not just the $\mathrm{Ni}$ acting as a catalyst for hydrogen association and dissociation: a nanoparticulate nickel boride phase is formed, which reversibly changes composition upon cycling and probably acts as a nucleus for phase transformations [155]. Another demonstration of the synergistic effects was the combination of a $\mathrm{TiCl}_{3}$-based

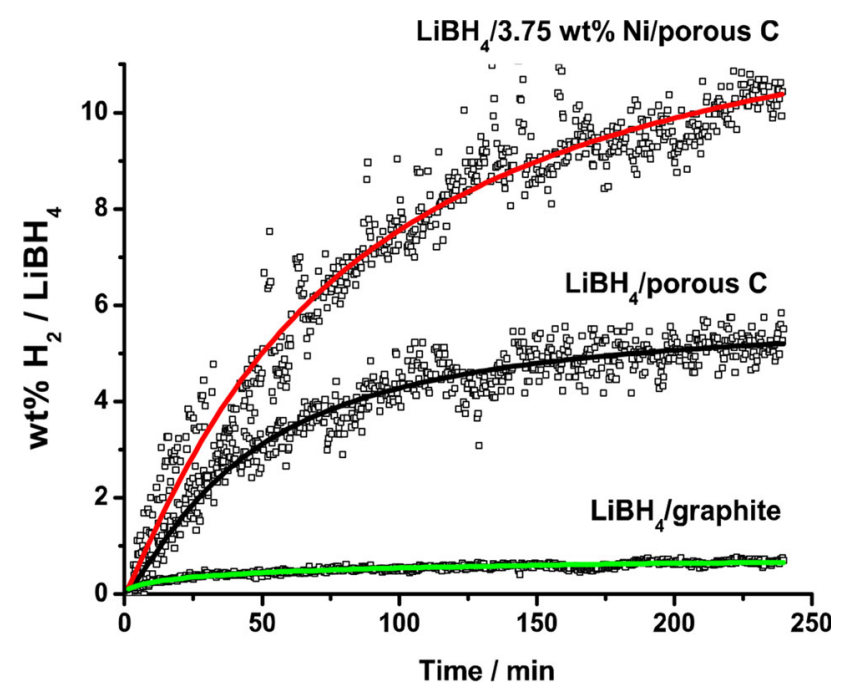

Fig. 6 Hydrogen absorption at $320{ }^{\circ} \mathrm{C}$ under 40 bar $\mathrm{H}_{2}$ after $\mathrm{H}_{2}$ desorption from macrocrystalline $\mathrm{LiBH}_{4}$ mixed with graphite, nanoconfined $\mathrm{LiBH}_{4}$ and nanoconfined $\mathrm{LiBH}_{4}$ with a $\mathrm{Ni}$ catalyst added. Details in Ref [154]

catalyst with nanoconfined $\mathrm{NaAlH}_{4}$. This nanocomposite showed significantly improved hydrogen desorption kinetics compared to either nanoconfined $\mathrm{NaAlH}_{4}$ alone or bulk $\mathrm{NaAlH}_{4}$ ball milled with $\mathrm{TiCl}_{3}$ [156]. An interesting recent approach is also combining metal hydrides with hydrogen gas-selective polymers, which might potentially protect against oxidation [157, 158].

\subsection{Impact of confinement on hydrogen release and reversibility}

Macrocrystalline complex metal hydrides such as $\mathrm{NaAlH}_{4}$ and $\mathrm{LiBH}_{4}$ typically only decompose and significantly release hydrogen above their melting point. Nanoconfinement leads 
to hydrogen release at temperatures well below the melting point, as well as increased cycleability [132, 150, 159-164]. For instance, low loadings of distinct supported $\mathrm{NaAlH}_{4}$ nanoparticles on carbon nanofibres, prepared by solution impregnation, release some hydrogen at room temperature, even without a Ti-based catalyst [131]. High loadings of $\mathrm{NaAlH}_{4}$, filling the host pores almost completely, result in a very good reversibility (>80-90\%) under relatively mild conditions without a catalyst [160, 161], but higher hydrogen release temperatures do not strongly correlate with pore size [160]. It has been postulated that this could be related to a dominating "catalytic" influence of the carbon [165, 166, 170]. However, probably more important is that not only the kinetics but also the phase equilibria are strongly influenced by nanoconfinement, as discussed in the next section.

Insight into the cycling of nanoconfined $\mathrm{NaAlH}_{4}$ is slowly emerging. Upon decomposition of $\mathrm{NaAlH}_{4}$, large Al crystallites are observed, which are expelled from the nanopores [166, 167]. This is not unexpected, as Al has a much larger surface energy than the $\mathrm{NaAlH}_{4}$ and does not wet the carbon matrix well. Nevertheless, upon rehydrogenation, the larger $\mathrm{Al}$ crystallites on the outside disappear, and nanoconfined $\mathrm{NaAlH}_{4}$ can be reformed [174]. As it is unlikely that the crystalline $\mathrm{Al}$ (with a melting point of $660{ }^{\circ} \mathrm{C}$ ) is very mobile, probably $\mathrm{Na}$ species as well as $\mathrm{NaAlH}_{4}$ are mobile on the carbon surface, which allows for the reformation of nanoconfined $\mathrm{NaAlH}_{4}$. For $\mathrm{LiBH}_{4}$, it has been reported that nanoconfinement changes the decomposition pathway and limits the emission of undesired decomposition products such as diborane [163, 164].

\subsection{Insight into changes in phase equilibria}

Nanoconfinement decreases the thermodynamic stability of complex metal hydrides due to the non-negligible contribution of the interface energy for small particles [150, 168]. However, equilibrium decomposition temperatures depend on the energy difference between hydrides and decomposition products, and hence on their interface energies. For $\mathrm{MgH}_{2}$, a decrease in stability is expected with nanosizing, as the surface energy of $\mathrm{MgH}_{2}$ is higher than that of $\mathrm{Mg}$ [169]. However, for complex hydrides like $\mathrm{LiBH}_{4}$ and $\mathrm{NaAlH}_{4}$, the reverse is expected, as their specific surface energies are much lower than those of their decomposition products. Hence, nanosizing complex metal hydrides will generally lead to an effective stabilization of the hydride phase, hence higher equilibrium decomposition temperatures than for macrocrystalline samples, as has been experimentally confirmed for $\mathrm{NaAlH}_{4}$ [153, 170]. However, in some cases, specific interactions with the carbon host are observed, which shift the phase equilibria in the desired direction. Reversible intercalation of $\mathrm{Li}$ or
$\mathrm{Na}$ into the carbon can occur, stabilizing the metal phase and hence lowering the equilibrium decomposition temperature, for instance, that of $\mathrm{NaH}$ under 1 bar $\mathrm{H}_{2}$ pressure from 425 to $225{ }^{\circ} \mathrm{C}$ [154, 171]. Also, lithium- and $\mathrm{Na}$ doped fullerenes are capable of reversibly storing $5 \mathrm{wt} \%$ hydrogen [172, 173].

\section{Mechanism of hydrogen sorption in alanates and borohydrides}

Since Bogdanovic et al. [174] presented the first experimentally determined isotherms for the hydrogen desorption and absorption in Ti-catalysed sodium alanate $\left(\mathrm{NaAlH}_{4}\right)$ at the Metal Hydrogen Conference in 1996, the role of the Ticatalyst and the hydrogen sorption mechanism of alanates has been intensively investigated. $\mathrm{NaAlH}_{4}$ desorbs hydrogen in three distinct steps, where $\mathrm{Na}_{3} \mathrm{AlH}_{6}$ and $\mathrm{NaH}$ are intermediate products of the partially dehydrogenated alanate in the process (Fig. 7):

$3 \mathrm{NaAlH}_{4} \rightarrow \mathrm{Na}_{3} \mathrm{AlH}_{6}+2 \mathrm{AlH}_{3} \rightarrow 3 \mathrm{NaH}+3 \mathrm{AlH}_{3}$,

which can also be written as follows, since $\mathrm{AlH}_{3}$ is rapidly dissociated:

$3 \mathrm{NaAlH}_{4} \rightarrow \mathrm{Na}_{3} \mathrm{AlH}_{6}+2 \mathrm{Al}+3 \mathrm{H}_{2} \rightarrow 3 \mathrm{NaH}+3 \mathrm{Al}+9 / 2 \mathrm{H}_{2}$

Adding up to $4 \mathrm{~mol} \%$ of $\mathrm{TiCl}_{3}$ to the $\mathrm{NaAlH}_{4}$ reduces the activation energies from 118 and 124 to 80 and $96 \mathrm{~kJ} / \mathrm{mol} \mathrm{H}_{2}$, respectively [175], and the isotherm of the reabsorption of hydrogen follows the desorption isotherm with small hysteresis $[174,175,177]$. The role of the Ti as a catalyst is to increase the reaction rate for the hydrogen desorption and absorption reaction, i.e. to allow the reaction to equilibrate in the time frame of the experiment [178]. The hydrogen desorption reaction rate increases linearly as a function of the $\mathrm{TiCl}_{3}$ that is added, up to $5 \mathrm{~mol} \%$; for larger quantities, the reaction rate does not increase anymore [176]. Despite years of intense investigations of a large variety of catalytic materials added to alanates, the mechanism of the catalysed reactions including the role of the catalyst remained until recently unresolved.

Quite a number of possible mechanisms for the hydrogen sorption in $\mathrm{MAlH}_{4}$ have been proposed [6, 179]. However, all these approaches suffer from the fact that $\mathrm{Ti}$ catalyses both hydrogen desorption steps as well as the adsorption of hydrogen. Based on purely thermodynamic considerations, a completely symmetrical mechanism can be drawn: Ti represents a bridging atom for the transfer of the $\mathrm{H}^{-}$and $\mathrm{M}^{+}$from one $\left[\mathrm{AlH}_{4}\right]^{-}$to the neighbouring one at the (de)hydrogenation steps (Fig. 6). On an atomistic level, the catalyst acts as a bridge to transfer the $(M \mathrm{H})$ or 
Fig. 7 Schematic representation of the enthalpy for the alanates a) and borohydrides formation and hydrogen desorption. While alanates show the hexahydride as intermediate, the borohydrides directly go to the elemental hydride. $\Delta \mathrm{H}_{\mathrm{f}}^{0}$ is the enthalpy of formation, $\Delta H_{\mathrm{m}}$ is the melting enthalpy, $\Delta \mathrm{H}_{\mathrm{des}}$ is the enthalpy of the hydrogen desorption, and $\Delta \mathrm{H}_{\mathrm{HM}}$ is the enthalpy of the elemental hydride

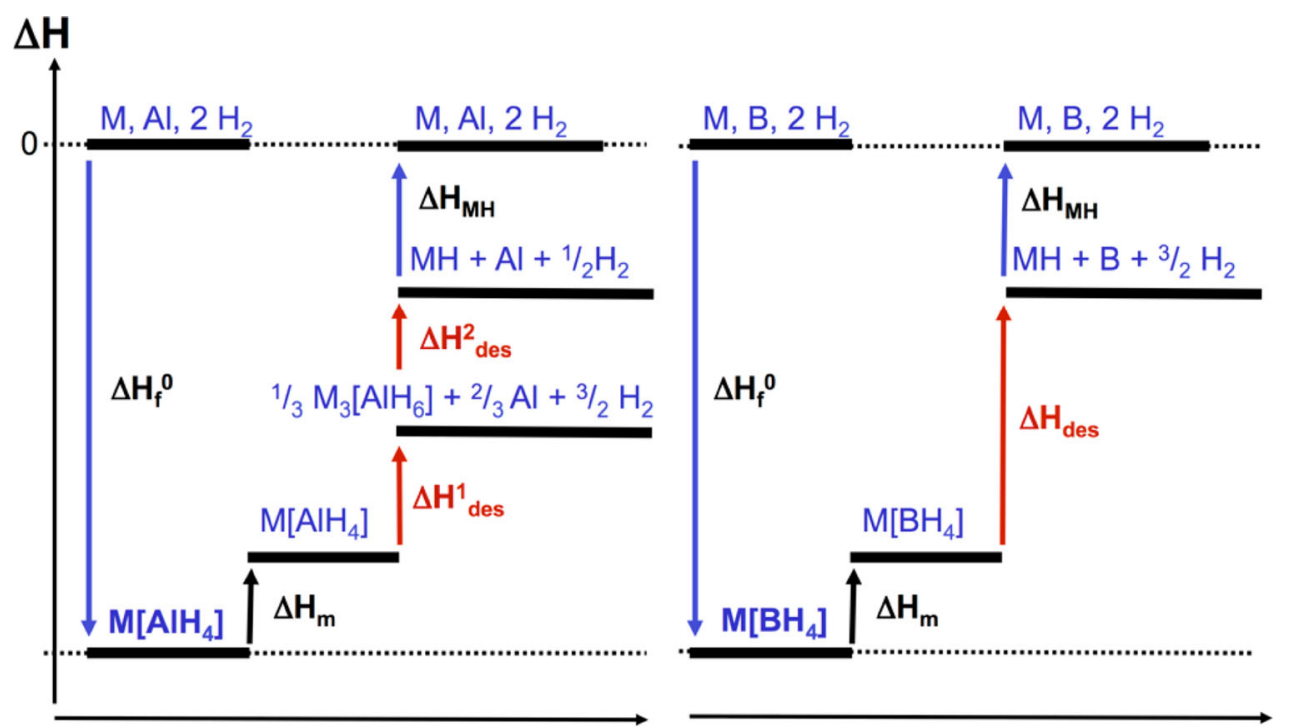

(a)

(b)
$M^{+}$and $\mathrm{H}^{-}$from one $\mathrm{NaAlH}_{4}{ }^{-}$to the neighbouring one to form $\mathrm{AlH}_{6}{ }^{3-}$ and finally to form $M \mathrm{H}$. This mechanism is symmetrical, and the role of the catalyst is to build a transition state $M^{+}-\mathrm{Ti}-\mathrm{H}^{-}$[180] (Fig. 8).

Several studies [182-184] report catalytic activity of additives in $\mathrm{LiBH}_{4}$; however, the result of doping $\mathrm{LiBH}_{4}$ with $\mathrm{TiCl}_{3}$ is not the formation of a totally reversible hydrogen storage system [185]. Recently, the formation of a volatile $\mathrm{Ti}\left(\mathrm{BH}_{4}\right)_{3}$ on the surface of the sample during the metathesis $\mathrm{TiCl}_{3}+\mathrm{LiBH}_{4}[186,187]$ was investigated to better understand the role of the $\mathrm{TiCl}_{3}$ addition [188]. The metathesis produces $\mathrm{Ti}\left(\mathrm{BH}_{4}\right)_{3}$ and $\mathrm{LiCl}$. Gaseous $\mathrm{Ti}\left(\mathrm{BH}_{4}\right)_{3}$ is formed on the surface of the sample and emitted. It decomposes into $\mathrm{TiH}_{2}$, diborane, boron and hydrogen. Titanium borohydride desorbs from the sample, depleting the element that is responsible for reversibility in the alanate systems. Rehydrogenation has been attempted. However, these experiments did not show the formation of $\mathrm{Ti}\left(\mathrm{BH}_{4}\right)_{3}$ [189]. The solid residue of the $\mathrm{TiCl}_{3}+\mathrm{LiBH}_{4}$ decomposition reaction is Ti-depleted and cannot reabsorb hydrogen. The active centres during the decomposition reaction of $\mathrm{TiCl}_{3}+\mathrm{LiBH}_{4}$ are identified as Ti-containing species. $\mathrm{Ti}\left(\mathrm{BH}_{4}\right)_{3}$ is extremely reactive, but it is the volatile product of a complete metathesis reaction. Although we cannot exclude the catalytic effect of Ti nanoimpurities in the residue sample, the measurements show that neither $\mathrm{Ti}\left(\mathrm{BH}_{4}\right)_{3}$ nor $\mathrm{TiCl}_{3}$ have a catalytic effect on $\mathrm{LiBH}_{4}$. The formation of $\mathrm{Ti}\left(\mathrm{BH}_{4}\right)_{3}$ through metathesis is the fundamental difference between alanates and borohydrides (Fig. 9).

For $\mathrm{TiCl}_{3}+\mathrm{NaAlH}_{4}$, no experimental evidence has been found for the formation of an analogous Ti-containing intermediate, such as $\mathrm{Ti}\left(\mathrm{AlH}_{4}\right)_{4}$. Even if such an

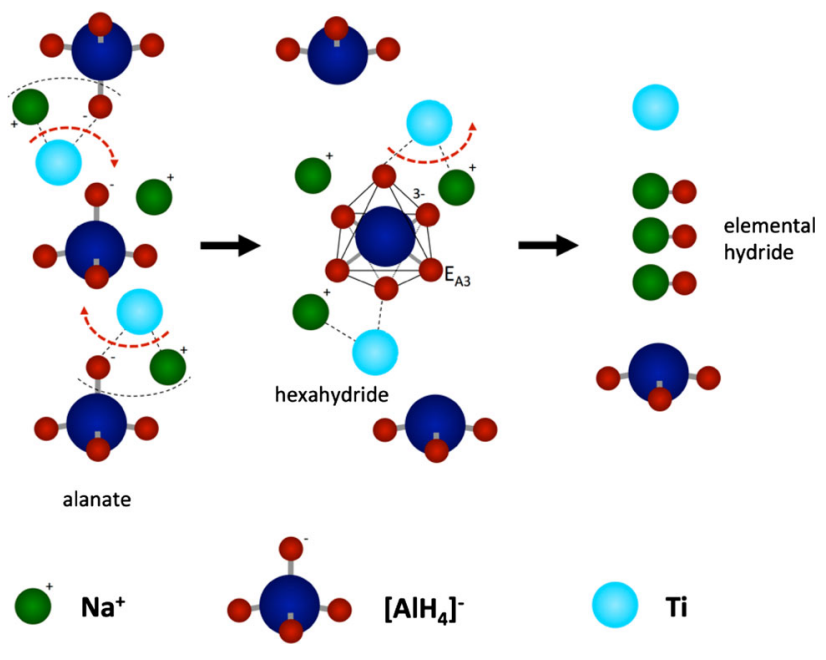

Fig. 8 Mechanism of the hydrogen desorption from $\mathrm{NaAlH}_{4}$. First two neighbouring $\mathrm{NaAlH}_{4}$ transfer a $\mathrm{NaH}$ to the central $\mathrm{NaAlH}_{4}$, which then becomes a $\mathrm{Na}_{3} \mathrm{AlH}_{6}$, leaving two $\mathrm{AlH}_{3}$. The role of the catalyst is to build a bridge for the $\mathrm{NaH}$, i.e. to allow the formation of a transition state where the charges are not completely separated $\mathrm{Na}^{+}-\mathrm{Ti}-\mathrm{H}[181]$

intermediate did exist, it would only be an intermediate step of the reaction, extremely unstable and immediately decomposed into solid components. Therefore, the elements $\mathrm{Al}, \mathrm{Na}$ and $\mathrm{Ti}$ stay in the solid phase, and hydrogen is the only emitted species during the dehydrogenation reaction. In the case of $\mathrm{TiCl}_{3}+\mathrm{LiBH}_{4}$, the formation of volatile $\mathrm{Ti}\left(\mathrm{BH}_{4}\right)_{3}$ has no impact on the dehydrogenation kinetics of $\mathrm{LiBH}_{4}$; it is not a catalyst. Because of the volatility of $\mathrm{Ti}\left(\mathrm{BH}_{4}\right)_{3}$, the $\mathrm{TiCl}_{3}+\mathrm{LiBH}_{4}$ system becomes Ti-depleted after the first desorption, preventing, under these conditions, the reversibility of the system. Creating a 
Fig. 9 Hydrogen desorption mechanism for $\mathrm{LiBH}_{4}$. First, the elemental hydride $\mathrm{LiH}$ is formed by transferring an $\mathrm{H}^{-}$ from $\mathrm{BH}_{4}^{-}$to the $\mathrm{Li}^{+}$, leaving a $\mathrm{BH}_{3}$. The $\mathrm{BH}_{3}$ at the surface has a high mobility and may either find another one to form $\mathrm{B}_{2} \mathrm{H}_{6}$ or release hydrogen

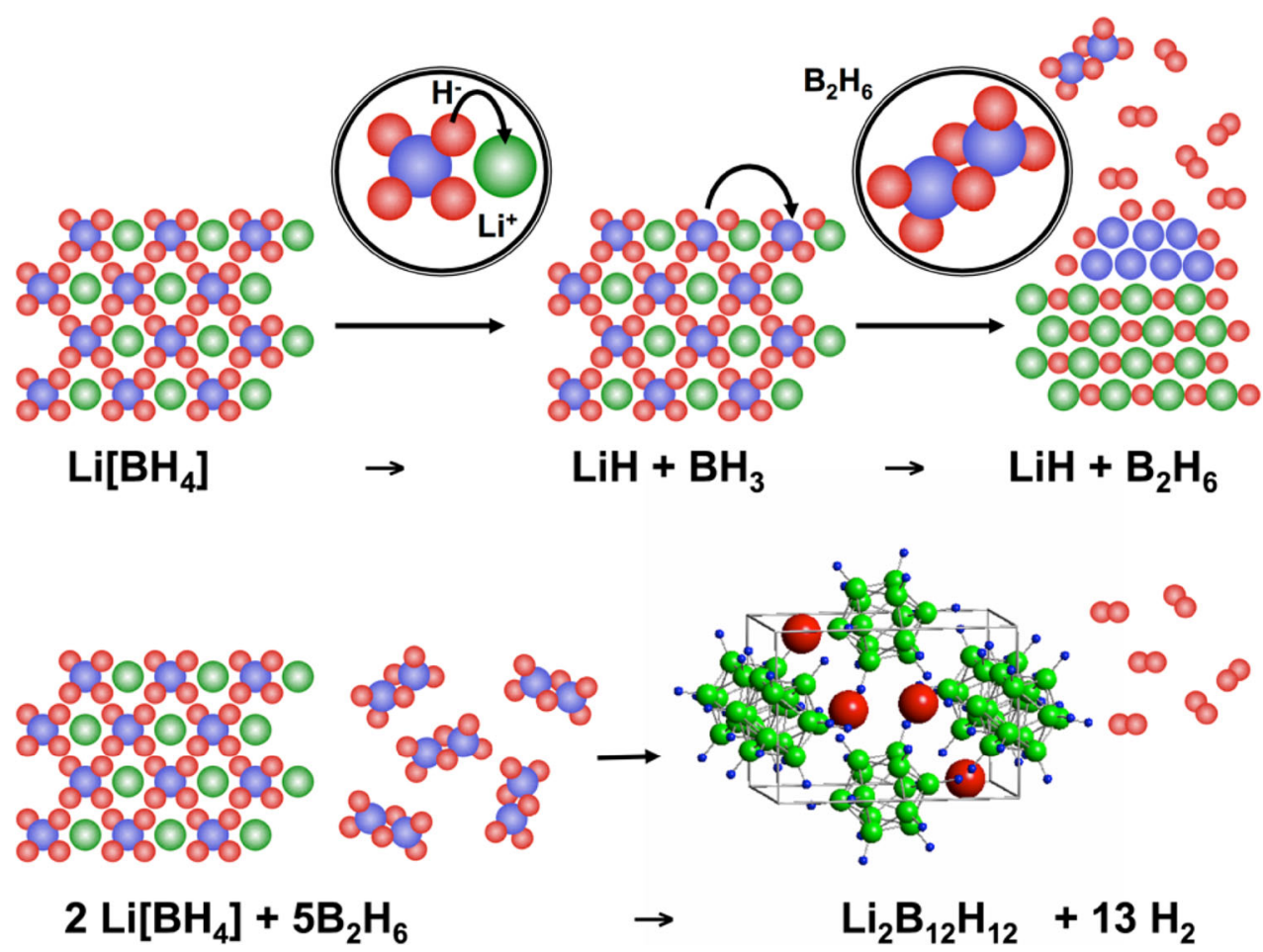

reversible hydrogen storage system based on borohydrides cannot simply be achieved with $\mathrm{Ti}$ additives because a metathesis reaction takes place that consumes the additive. On the contrary, a clear catalytic effect is the reason for the enhancement of hydrogen sorption kinetics in alanates, whose mechanisms have been explained above.

Peculiar for the borohydrides, the emission of diborane has also been intensively investigated. The emission of this gas is related to the thermodynamic stability of the borohydrides themselves. Borohydrides whose cations are highly electronegative (roughly $E N>1.3$ ) release a significant amount of diborane during decomposition [17, 190], while the more stable ones, whose cations are less electronegative $(E N<1.3)$, emit diborane at the impurity level only [21] and above $200{ }^{\circ} \mathrm{C}$. This provides a reliable way of predicting and tuning the properties of this class of materials for hydrogen storage [191].

\section{Reactive hydride composites}

As shown by Reilly and Wiswall [192], the total reaction enthalpy as well as the desorption temperature of metal and complex hydrides can be lowered by adding a reactant that reacts reversibly or irreversibly with an element or several elements of the hydride to form a stable compound. One such reversible system consisting of a complex hydride and such a reactant is [193]
$2 \mathrm{LiBH}_{4}+\mathrm{Al} \rightleftarrows 2 \mathrm{LiH}+\mathrm{AlB}_{2}+3 \mathrm{H}_{2}$

$\mathrm{LiBH}_{4}$ is highly interesting as hydrogen storage material because of its high gravimetric storage density of $18 \mathrm{wt} \%$. Aluminium is a low-cost potential destabilizing agent for $\mathrm{LiBH}_{4}$, yielding a theoretical $8.6 \mathrm{wt} \%$ of hydrogen for a 2:1 $\left(\mathrm{LiBH}_{4} / \mathrm{Al}\right)$ molar ratio.

However, measured values are lower. For example, Kang et al. [194] showed a ball-milled 2:1 ratio forming $\mathrm{AlB}_{2}$ and $\mathrm{LiH}$ upon dehydrogenation at $450{ }^{\circ} \mathrm{C}$ and releasing $7.2 \mathrm{wt} \%$ of hydrogen after $3 \mathrm{~h}$. Rehydrogenation to $5.1 \mathrm{wt} \%$ was only achieved at $400{ }^{\circ} \mathrm{C}$ under 100 bar of $\mathrm{H}_{2}$. The predicted $\mathrm{T}(1 \mathrm{bar})$ of $188^{\circ} \mathrm{C} 197$ ] is not observed due to uncertainty in the enthalpy of formation for $\mathrm{AlB}_{2}$. For example, Friedrichs et al. [195] estimated that T(1 bar) would be reached at a much higher temperature of about $335{ }^{\circ} \mathrm{C}$.

Another approach is to use $\mathrm{LiAlH}_{4}[196,197]$ or $\mathrm{NaAlH}_{4}$ [198] as a source of $\mathrm{Al}$ in order to produce highly dispersed, oxide-free $\mathrm{Al}$ through the in situ decomposition of $\mathrm{LiAlH}_{4}$ or $\mathrm{NaAlH}_{4}$. The $\mathrm{Al}$ dispersion may be improved by decomposing the more brittle alanate during milling, rather than trying to mill ductile $\mathrm{Al}$. $\mathrm{TiCl}_{3}$ is observed to be a more suitable catalyst precursor than $\mathrm{TiF}_{3}$, as no hexaalanate phase was identified $[199,200]$. Using this approach, Meggough et al. [197] showed an onset decomposition temperature for $\mathrm{LiBH}_{4}$ starting at around $290{ }^{\circ} \mathrm{C}$ compared to $380{ }^{\circ} \mathrm{C}$ for pure $\mathrm{LiBH}_{4}$. The enthalpy 
of dehydrogenation was $38.2 \mathrm{~kJ} \mathrm{~mol}^{-1}\left(\mathrm{H}_{2}\right)$, and, depending on the entropy of the destabilization reaction, a range of $240-300{ }^{\circ} \mathrm{C}$ for $\mathrm{T}$ ( 1 bar).

Unfortunately, these systems have a significant loss in capacity upon cycling, depending on the catalysts as well as the preparation method used [185, 194, 195, 197]. This may be diffusion related, as $\mathrm{LiH}, \mathrm{AlB}_{2}$ and $\mathrm{B}$ are physically apart and unable to reform into $\mathrm{LiBH}_{4}$ and $\mathrm{Al}$, or there may be a formation of a boride shell on the surface of the $\mathrm{Al}$ particles, preventing the complete reaction of $\mathrm{Al}$ and $\mathrm{B}$ into $\mathrm{AlB}_{2}$ [197], as seen in Fig. 10. This has advantages, in that it prevents available $\mathrm{Al}$ with $\mathrm{LiH}$ from forming $\mathrm{LiAl}$ above $400{ }^{\circ} \mathrm{C}$, which would also lead to a lowering of the reversible capacity. Therefore, it may be possible to improve the cycling ability of the system by optimizing the $\mathrm{Al}$ dispersion further so that the $\mathrm{Al}$ clusters are small enough to completely react, forming $\mathrm{AlB}_{2}$ with no core.

A detailed investigation of the decomposition reactions and decay in the hydrogen storage capacity during repeated hydrogen release and uptake up to ten cycles for the reactive composite $\mathrm{LiBH}_{4}-\mathrm{Al}(2: 3)$ is conducted with and without the additive titanium boride, $\mathrm{TiB}_{2}[201,202]$. The decomposition of $\mathrm{LiBH}_{4}-\mathrm{Al}$ results in the formation of $\mathrm{LiAl}, \mathrm{AlB}_{2}$ and $\mathrm{Li}_{2} \mathrm{~B}_{12} \mathrm{H}_{12}$ via several reactions and intermediate compounds. The $\mathrm{TiB}_{2}$ additive appears to have a limited effect on the decomposition pathway of the samples, but seems to facilitate formation of intermediate species at lower temperatures compared to the sample without any additives. Solid solutions of $\mathrm{Li}_{x} \mathrm{Al}_{1-x} \mathrm{~B}_{2}$ or
$\mathrm{Al}_{1-x} \mathrm{~B}_{2}$ are observed during decomposition, and from Rietveld refinement, the composition of the solid solution is estimated to be $\mathrm{Li}_{0.22} \mathrm{Al}_{0.78} \mathrm{~B}_{2}$. The intercalation of $\mathrm{Li}$ in the $\mathrm{AlB}_{2}$ structure is further investigated by the $\mathrm{B}[14]$ and $\mathrm{Al}$ MAS NMR [30] spectra of the $\mathrm{LiH}-\mathrm{AlB}_{2}$ and $\mathrm{AlB}_{2}$ samples. Hydrogen release and uptake for $\mathrm{LiBH}_{4}-\mathrm{Al}$ reveal a significant loss in the hydrogen storage capacity; that is, after four cycles a capacity of about $45 \%$ remains, and after ten cycles the capacity is degraded to approximately $15 \%$ of the theoretically available hydrogen content. This capacity loss may be due to the formation of $\mathrm{Li}_{2} \mathrm{~B}_{12} \mathrm{H}_{12}$ as observed by B MAS NMR [14] and Raman spectroscopy [202].

The structural evolution of a 1:1 molar ratio $\mathrm{LiBH}_{4}$ :$\mathrm{LiAlH}_{4}$ system [203] showed a multi-step reaction with a total weight loss of $6.8 \mathrm{wt} \%$ of $\mathrm{H}_{2}$ at $430{ }^{\circ} \mathrm{C}$. An in situ SR-PXD experiment showed the onset decomposition temperature of molten $\mathrm{LiBH}_{4}$ as being $50{ }^{\circ} \mathrm{C}$ less than that of pure $\mathrm{LiBH}_{4}$. In the range $328-380{ }^{\circ} \mathrm{C}$, the molten $\mathrm{LiBH}_{4}$ reacts with $\mathrm{Al}$ particles, forming an unidentified phase of $\mathrm{Li}-\mathrm{B}-\mathrm{Al}-\mathrm{H}$ atoms identified by MAS NMR measurements.

To keep or even increase the high storage capacity of lightweight hydrides, however, it is necessary to use as a reactant another hydride or several other hydrides. While such systems, which are called reactive hydride composites [204], show rather complex reaction pathways, they exhibit extremely high reversible storage capacities under more or less moderate conditions.

Many such systems are mixtures of a complex and a metal hydride.

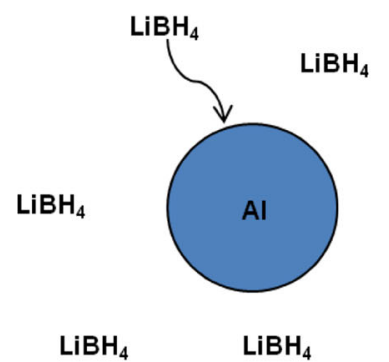

$\mathrm{LiBH}_{4}$

$\mathrm{LiBH}_{4}$

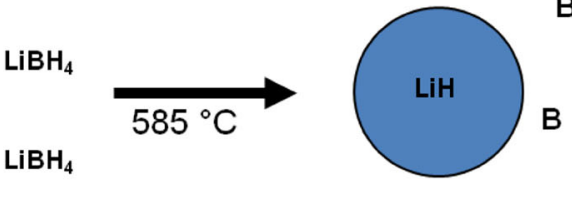

$\mathrm{LiBH}_{4}$

(1)

B
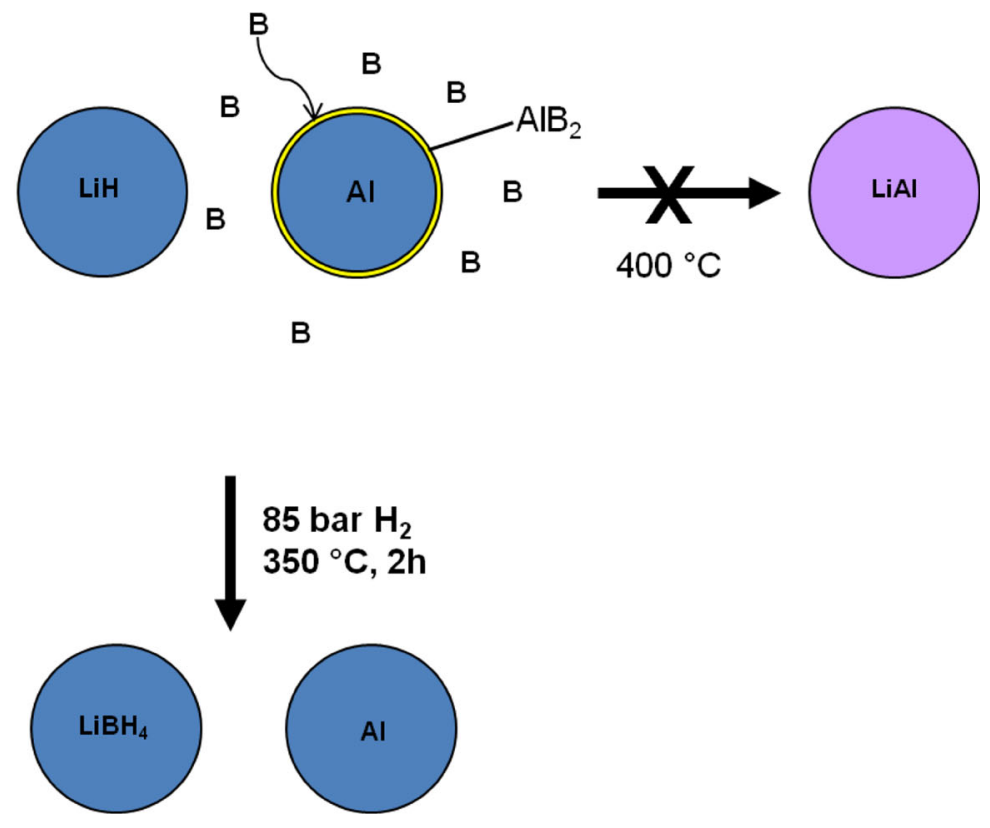

Fig. 10 Schematic representation of the formation of an $\mathrm{AlB}_{2}$ shell around an $\mathrm{Al}$ particle, preventing the formation of $\mathrm{LiAl}$ and the reformation of $\mathrm{LiBH}_{4}$ 
One very well-known and intensively studied system is the $2 \mathrm{LiBH}_{4}-\mathrm{MgH}_{2}$ system [102, 205]. It shows a reversible hydrogen storage capacity in the range of $8-11 \mathrm{wt} \%$ and rather stable cycling properties [206]. Due to the lowered amount of reaction enthalpy, which accounts to 40-50 kJ/mol $\mathrm{H}_{2}$ [102, 207] during hydrogenation, much less heat is produced if compared with both $\mathrm{LiBH}_{4}$ and $\mathrm{MgH}_{2}$, and dehydrogenation is possible at temperature and pressure conditions that are not suitable for dehydrogenation of the single $\mathrm{LiBH}_{4}$ [208, 209]. Nevertheless, due to the high activation barrier for desorption, the dehydrogenation temperature is above $350{ }^{\circ} \mathrm{C}$ for bulk material and above $250{ }^{\circ} \mathrm{C}$ for the composite in nanoscaffolds. The aband desorption properties can be improved by the addition of some mol\% of transition metal compounds, which in many cases form very small boride nanoparticles during the ball milling and/or heating processes [210]. These boride nanoparticles very likely act as heterogeneous nucleation sites for the $\mathrm{MgB}_{2}$ phase during desorption and therefore lead to a much finer phase distribution in the system and much better kinetics and cycling stability [211].

In the ideal case of the so-called "mutually destabilized" reactive hydride composites, however, both the components of the reactive hydride composites destabilize each other at the same time. In this case, the dehydrogenation temperature of the composite should be lower than that of the less stable component. $\mathrm{LiBH}_{4}-\mathrm{CaH}_{2}[212-$ 214], $\mathrm{LiBH}_{4}-\mathrm{CeH}_{2+x}[215,216], \mathrm{LiBH}_{4}-\mathrm{YH}_{3}$ [217] and the $\mathrm{Mg}\left(\mathrm{NH}_{2}\right)_{2}-\mathrm{LiH}$ [218] systems are known examples of these mutually destabilized RHCs. The main thermodynamic driving force to decrease the dehydrogenation temperature of them is the formation of more stable dehydrogenation products such as metal borides $\left(\mathrm{CaB}_{6}, \mathrm{CeB}_{6}\right.$ and $\left.\mathrm{YB}_{4}\right)$ or mixed imide $\left(\mathrm{Li}_{2} \mathrm{Mg}(\mathrm{NH})_{2}\right)$.

The first discovered reactive hydride composites are amide-hydride systems [219], among which the $\mathrm{Mg}\left(\mathrm{NH}_{2}\right)_{2}-2 \mathrm{LiH}$ composite possesses some very attractive features, e.g. ca. $5.5 \mathrm{wt} \%$ hydrogen content [218, 220-222] $\sim 40 \mathrm{~kJ}\left(\mathrm{molH}_{2}\right)^{-1}$ heat of desorption, theoretically allowing the release of $0.1 \mathrm{MPa}$ hydrogen at ca. $353 \mathrm{~K}$ and good reversibility. The research efforts in the past few years have focused on kinetic and thermodynamic improvements to this composite through the introduction of effective additives. As shown in Fig. 2, the addition of $1.5 \mathrm{~mol} \%$ triphenyl phosphate (TPP) leads to a ca. $15 \mathrm{~K}$ decrease in the hydrogen desorption peak temperature, which was ascribed to the TPP being able to prevent the material from aggregation/crystallization during the cycling tests [223]. Mixing $3 \mathrm{~mol} \% \mathrm{KH}$ with the material results in an even more pronounced kinetic improvement, i.e. a ca. $50 \mathrm{~K}$ peak temperature drop [224, 225]. Information derived from designed experiments and spectroscopic characterization indicates that $\mathrm{KH}$ actively participates in dehydrogenation by interacting with $\mathrm{Mg}\left(\mathrm{NH}_{2}\right)_{2}$ and the intermediate $\mathrm{LiNH}_{2}$, forming $\mathrm{K}_{2}$ $\mathrm{Mg}\left(\mathrm{NH}_{2}\right)_{4}$ and $\mathrm{Li}_{3} \mathrm{~K}\left(\mathrm{NH}_{2}\right)_{4}$. Those $K$-containing species likely transform circularly in the dehydrogenation $\left[\mathrm{KH} \leftrightarrow \mathrm{K}_{2} \mathrm{Mg}\left(\mathrm{NH}_{2}\right)_{4} \leftrightarrow \mathrm{KLi}_{3}\left(\mathrm{NH}_{2}\right)_{4}\right]$ that creates a more energy favourable pathway. The necessity for further kinetic enhancement, however, depends on the improvement of the thermodynamic properties of this composite to allow 0.1 MPa equilibrium desorption pressure at lower temperatures, especially in the ambient temperature range. $\mathrm{Hu}$ et al. [226] reported that the addition of $10 \mathrm{~mol} \%$ $\mathrm{LiBH}_{4}$ to the $\mathrm{Mg}\left(\mathrm{NH}_{2}\right)_{2}-2 \mathrm{LiH}$ composite reduced the heat of dehydrogenation from 39 to $36.5 \mathrm{~kJ}\left(\mathrm{molH}_{2}\right)^{-1}$. The addition of a few molar per cent of $\mathrm{LiBr}$ also leads to a reduced heat of hydrogen desorption [227]. More recently, a strategy in improving the thermodynamic properties by forming a more stable intermediate has been developed. By introducing stoichiometric amounts of $\mathrm{LiI}, \mathrm{LiBr}$ or $\mathrm{LiBH}_{4}$ to the composite, hydrogen release at $0.1 \mathrm{MPa}$ equilibrium pressure is thermodynamically allowed at 333, 320 or $337 \mathrm{~K}$, respectively, which are tens of degrees Celsius lower than the neat composite [228] (see Fig. 11). Although the efforts above are encouraging in bringing this composite material a step closer to the practical application, the gap between thermodynamic and kinetic temperatures is still a pending subject for further investigation.

Another example for RHCs is the $\mathrm{LiBH}_{4}-\mathrm{Ca}\left(\mathrm{BH}_{4}\right)_{2}$ system, where both the components are high-capacity complex hydrides and the theoretical maximum reversible hydrogen storage capacity is $12.8 \mathrm{wt} \%$, which is the height capacity among known RHC systems [71, 229].

Other examples of mutual destabilization systems containing two different complex metal hydrides may include the $\mathrm{LiBH}_{4}-\mathrm{Y}\left(\mathrm{BH}_{4}\right)_{3}$ [230] and $\mathrm{LiBH}_{4}-\mathrm{Mg}\left(\mathrm{BH}_{4}\right)_{2}$ systems [72]. However, it is still not clear whether there is clear

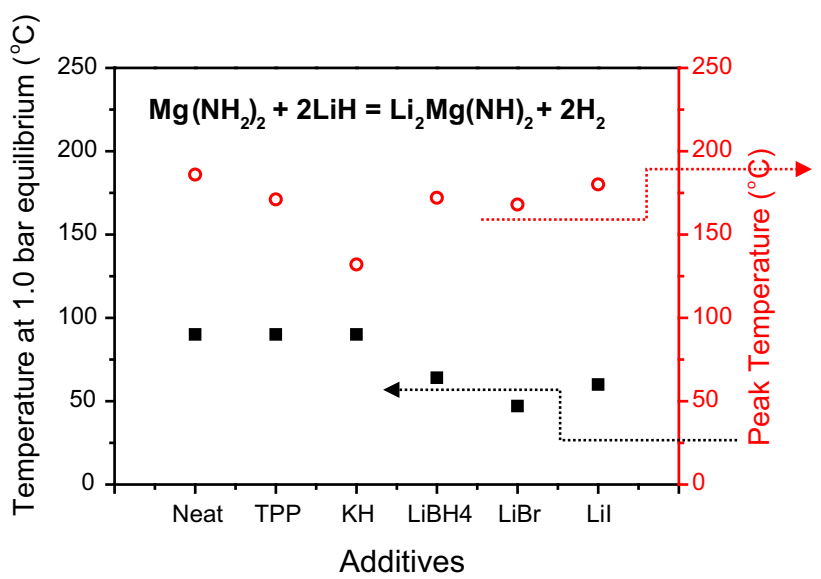

Fig. 11 Hydrogen desorption property of the $\mathrm{Mg}\left(\mathrm{NH}_{2}\right)_{2}-2 \mathrm{LiH}$ composite optimized with different additives 
evidence supporting the direct destabilizing reaction between $\mathrm{LiBH}_{4}$ and the other metal borohydrides, as they can also form stable metal borides by themselves without any reaction with $\mathrm{LiBH}_{4}$.

There are a number of issues to be addressed on the RHCs, including the mutually destabilizing systems. The first and the most complicated one is the dehydrogenation reaction path under the given thermodynamic conditions. We tend to describe only the overall reaction, which, in most cases, is too simplified to represent the actual reaction occurring. Quite often, more than two closely competing dehydrogenation reactions can proceed almost simultaneously, particularly when the thermodynamic conditions under which the dehydrogenation reaction being undergone is continuously changing. The observation of different types of closo-boranes during or after the dehydrogenation reaction of the RHCs, including borohydrides, is a good example. These mostly amorphous higher borane byproducts are quite stable thermodynamically, and they seem to be more difficult to rehydrogenate than the competing metal borides. Another issue is the influence of the hydrogen back/partial pressure on the formation of the dodecaboranes instead of metal borides [231-233]. When the dehydrogenation reaction occurs below a critical hydrogen partial pressure at a given temperature, it tends to form dodecaborane, which seems not to readily react with the metal hydrides to form metal borides. All these factors not only change the dehydrogenation reaction paths but also significantly control the degree of reversibility and cycle properties. Without a clear understanding of the role of these thermodynamic parameters in both the dehydrogenation and rehydrogenation reactions, it would be very difficult to control the reactions to increase the reversible storage capacity as well as the cycle performance for practical applications. Other issues include the seemingly inherent slow reaction kinetics between different phases in the composites. However, this problem can be dealt with by adopting effective catalytic additives together with microstructure control methods such as nanostructuring or nanoconfinement [229].

Although the dehydrogenation temperatures of the RHCs are lower than those of the individual hydrides, a further decrease in dehydrogenation temperature down to around $100{ }^{\circ} \mathrm{C}$ has not yet been experimentally observed, even though there are a couple of RHCs with predicted or extrapolated values of the equilibrium dehydrogenation temperatures below $100{ }^{\circ} \mathrm{C}$ [193, 234]. One possible way to realize this challenging goal is to combine high-capacity (complex) metal hydrides with a third element/compound that may promote the formation of even more stable dehydrogenation products with a reaction enthalpy preferably below $35 \mathrm{~kJ} / \mathrm{molH}_{2}$.

\section{Liquid hydrides}

Liquid hydrides have long been considered for vehicular applications given the practicality of transport within the existing infrastructure [235, 236]. An early approach utilized in Chrysler's "Natrium" relied on the exothermic release of $\mathrm{H}_{2}$ from aqueous solutions of $\mathrm{NaBH}_{4}$. While this approach did not require additional heat to release $\mathrm{H}_{2}$, it does face three significant challenges that limit practical application: (1) aqueous solutions of $\mathrm{NaBH}_{4}$ are not thermally stable and require caustic stabilizers; (2) the hydrolysis products are less soluble than $\mathrm{NaBH}_{4}$ and precipitate in the reactor; and (3) regeneration of $\mathrm{NaBH}_{4}$ requires costly off-board chemical reduction. Work on the development of more stable borohydrides followed; for example, $\mathrm{Xu}$ [237] investigated the properties of aqueous ammonia borane and found this to be significantly more stable than $\mathrm{NaBH}_{4}$. Another material with greater stability is $\mathrm{NaB}_{3} \mathrm{H}_{8}$, synthesized and investigated by Shore [238]. Schubert [239] noted that the $\mathrm{NaB}_{3} \mathrm{H}_{8}$ provided the added advantage of greater solubility of both the starting material and the products, in part due to the formation of a mixture of products upon $\mathrm{H}_{2}$ release.

Organic liquids, as opposed to aqueous solutions, have also been extensively investigated as liquid hydrogen carriers. Computational screening studies of cyclic endothermic hydrides showed that inclusion of heteroatoms, e.g. $\mathrm{N}$ or $\mathrm{O}$, promotes hydrogen release at significantly lower temperatures [240]. Liu [241] incorporated an aminoborane function into a cyclic hydrocarbon to produce $\mathrm{C}-\mathrm{B}-\mathrm{N}$ compounds with significantly enhanced thermal stability. The liquid CBN materials could also be used to dissolve hydrogen-rich materials such as ammonia borane to provide an even higher density of hydrogen. This approach had two additional advantages: faster rates of $\mathrm{H}_{2}$ release and the formation of eutectic product mixtures that reduce the melting point to provide a greater temperature range where the materials remain liquid [242].

The challenges still facing liquid carriers include efficient regeneration, development of heterogeneous catalysts and minimizing the gas/solid/liquid interface when large quantities of $\mathrm{H}_{2}$ are released. Jensen [243] has initiated an approach using homogeneous catalysts to circumvent this latter issue. The catalysts under consideration are sufficiently active and low cost to enable $\mathrm{H}_{2}$ release at moderate temperatures to provide the optimum onboard efficiency.

Liquid compounds based on metal borohydrides have also been developed. For the $p$-element complex hydrides, the existence of the liquid aluminium tetrahydroborate $\mathrm{Al}\left(\mathrm{BH}_{4}\right)_{3}$ is known. This compound is very difficult to handle (instable and explosive in contact with air); 
however, other p-element complex hydrides are possibly liquid at room temperature. Very little experimental information about the physical properties (especially thermodynamic properties, e.g. stability) is available in the literature for the complex hydrides [239, 244]. Only a few compounds benefiting from their large production are used in chemical processes and have been investigated in more detail (e.g. $\mathrm{LiBH}_{4}, \mathrm{NaBH}_{4}$ ). Empirical relationships between the decomposition/melting temperature and the electronegativity of the constituting ions have been developed. These empirical relationships are useful tools for deducing properties of complex hydrides that are not fully characterized and have allowed for identification of potentially liquid hydrides among the $p$-element complex hydrides (e.g. tetrahydroborates of $\mathrm{Be}, \mathrm{Ti}, \mathrm{V}, \mathrm{Cr}, \mathrm{Mn}, \mathrm{Zn}$ or tetrahydroalanates of $\mathrm{Mg}$ or $\mathrm{Y}$ ). These elements need to now be synthesized and subsequently characterized in order to confirm their potential for hydrogen storage. Three somehow new families of hydrides potentially interesting for hydrogen storage, the alkyl complex hydride, the triple complex hydrides and the hydrido tetrahydroborates, have been identified. Alkyl complex hydrides [245] such as $\mathrm{MeAl}\left(\mathrm{BH}_{4}\right)_{2}, \mathrm{GaMe}_{2}\left(\mathrm{BH}_{4}\right), \mathrm{LiBHEt}_{3}$ and $\mathrm{NaAlH}_{2}\left(\mathrm{OCH}_{2}\right.$ $\left.\mathrm{CH}_{2} \mathrm{OCH}_{3}\right)_{2}$ are compounds that are liquid or viscous at ambient conditions, with a very high gravimetric density in the case of $\mathrm{MeAl}\left(\mathrm{BH}_{4}\right)_{2}(11.2$ mass \% without considering the hydrogen of the methyl Me). Triple complex hydrides [246] such as $\mathrm{LiAlH}_{4} \mathrm{BH}_{3}, \mathrm{LiAlH}_{4}\left(\mathrm{BH}_{3}\right)_{2}$ and $\mathrm{LiGaH}_{4}(-$ $\left.\mathrm{BH}_{3}\right)_{4}$ have low decomposition temperatures (in the range of 60 to $200{ }^{\circ} \mathrm{C}$ ) and very high gravimetric densities (in the range of 10.6 to 15.4 mass\%). Triple complex hydrides are in fact double complex hydrides stabilized by adding a third compound or atom group.

The unstable and difficult to handle $\mathrm{Al}\left(\mathrm{BH}_{4}\right)_{3}$ is stabilized by the addition of lithium chloride, creating $\mathrm{LiAlH}_{3} \mathrm{Cl}\left(\mathrm{BH}_{3}\right)_{3}$, which is easy to handle. $\mathrm{Al}\left(\mathrm{BH}_{4}\right)_{3}$ contained in the triple complex hydride can be desorbed (with an efficiency of $98 \%$ ) by heating over $100{ }^{\circ} \mathrm{C}$ (subsequently, the liberation of hydrogen of the $\mathrm{Al}\left(\mathrm{BH}_{4}\right)_{3}$ occurs only at around $125^{\circ} \mathrm{C}$ ); moreover, the addition of lithium chloride for the stabilization has been claimed to be reversible. Hydrido tetrahydroborates [247] contain in particular $\mathrm{HAl}\left(\mathrm{BH}_{4}\right)_{2}$, which is viscous and non-volatile at room conditions, with a very high hydrogen content of $15.7 \mathrm{wt} \%$. Further experimental and theoretical research on the stability and the reversibility of these new materials is needed as well as a deeper characterization of their physical properties (thermal and electronic/structural). This will lead to accurate models of stability, allowing the finding, the choice and possibly the tailoring of new, very efficient compounds for mobile hydrogen storage.

\section{Conclusions}

Recent achievements of the workgroup "Complex and liquid hydrides" of the International Energy Agency (IEA) Task 32 " $\mathrm{H}_{2}$-Based Energy Storage" were presented.

Specifically, we discussed the physical and chemical properties of complex hydrides, as a candidate for hydrogen storage materials. Different challenges related to complex hydrides were addressed: their synthesis, showing routes for the production of novel metal borohydrides; their thermodynamic stability, presenting theoretical and empirical models to predict their thermodynamic properties; their reaction mechanism, analysing the effect of additives to the hydrogen sorption reactions and of nanoconfinement; their development, combining different complexes to form reactive composite hydrides; and their peculiarities, illustrating an interesting call of materials, liquid at room temperature.

The work of this task represents the combination of expertise and technology and the presented overview represents the state-of-the-art research on energy storage in complex and liquid hydrides.

Acknowledgments Financial support from the Federal Office of Energy in Switzerland for the Project No. SI/500597 "Advanced Complex Hydrides (ACH)" and the IEA Task 32 participation are acknowledged. This work was financially supported by CCEM research through the HyTech project and the SCCER "Heat \& Electricity Storage" programme. The work was supported by the Danish National Research Foundation, Center for Materials Crystallography (DNRF93), the Danish Council for Strategic Research (project HyFill-Fast) and the Danish Research Council for Nature and Universe (Danscatt). We are grateful to the Carlsberg Foundation and Energistyrelsen, EUDP.

\section{References}

1. L. Quai et al., ChemSusChem. doi:10.1002/cssc.201500231

2. A. Züttel, A. Borgschulte, L. Schlapbach, Hydrogen as a Future Energy Carrier (Wiley-VCH, Weinheim, 2008), pp. 427. ISBN: 978-3-527-30817-0

3. Y. Nakamori, K. Miwa, Phys. Rev. B 74, 045126(1)-045126(9) (2006)

4. S. Takagi, S. Orimo, Scr. Mater. (Viewpoint Paper) 109, 1-5 (2015)

5. A. Borgschulte et al., Phys. Chem. Chem. Phys. 10, 4045 (2008)

6. T. Frankcombe, Chem. Rev. 112, 2164 (2012)

7. A. Borgschulte, E. Callini, B. Probst, A. Jain, S. Kato, O. Friedrichs, A. Remhof, M. Bielmann, A. Ramirez-Cuesta, A. Züttel, J. Phys. Chem. C 115, 17220 (2011)

8. L.H. Jepsen, M.B. Ley, Y.-S. Lee, Y.W. Cho, M. Dornheim, J.O. Jensen, Y. Filinchuk, J.E. Jørgensen, F. Besenbacher, T.R. Jensen, Mater. Today 17, 129-135 (2014)

9. M.B. Ley, L.H. Jepsen, Y.-S. Lee, Y.W. Cho, J.M. Bellosta von Colbe, M. Dornheim, M. Rokni, J.O. Jensen, M. Sloth, Y. Filinchuk, J.E. Jørgensen, F. Besenbacher, T.R. Jensen, Mater. Today 17, 122-128 (2014) 
10. D.B. Ravnsbæk, Y. Filinchuk, R. Černý, M.B. Ley, Dr Haase, H.J. Jakobsen, Jr Skibsted, T.R. Jensen, Inorg. Chem. 49, 3801-3809 (2010)

11. C. Frommen, N. Aliouane, S. Deledda, J.E. Fonneløp, H. Grove, K. Lieutenant, I. Llamas-Jansa, S. Sartori, M.H. Sørby, B.C. Hauback, J. Alloy. Compd. 496, 710-716 (2010)

12. T. Sato, K. Miwa, Y. Nakamori, K. Ohoyama, H.-W. Li, T. Noritake, M. Aoki, S. Towata, S. Orimo, Phys. Rev. B 77, 104114(1)-104114(8) (2008)

13. T. Jaron, W. Grochala, Dalton Trans. 39, 160-166 (2010)

14. Y.-S. Lee, J.-H. Shim, Y.W. Cho, J. Phys. Chem. C 114, 12833-12837 (2010)

15. D.B. Ravnsbæk, L.H. Sørensen, Y. Filinchuk, D. Reed, D. Book, H.J. Jakobsen, F. Besenbacher, J. Skibsted, T.R. Jensen, Eur. J. Inorg. Chem. 11, 1608-1612 (2010)

16. J. Huot, D.B. Ravnsbæk, J. Zhang, F. Cuevas, M. Latroche, T.R. Jensen, Prog. Mater Sci. 58, 30-75 (2013)

17. H. Hagemann, M. Longhini, J.W. Kaminski, A. Wesolowski, R. Cerny, N. Penin, M.H. Sørby, B.C. Hauback, G. Severa, C.M. Jensen, J. Phys. Chem. A 112, 7551-7555 (2008)

18. D. Ravnsbæk, Y. Filinchuk, Y. Cerenius, H.J. Jakobsen, F. Besenbacher, J. Skibsted, T.R. Jensen, Angew. Chem. Int. Ed. 48, 6659 (2009)

19. R. Ĉerný, D.B. Ravnsbæk, P. Schouwink, Y. Filinchuk, Y. Penin, J. Teyssier, L. Smrčok, T.R. Jensen, J. Phys. Chem. C 116, 1563 (2012)

20. O. Friedrichs, A. Borgschulte, S. Kato, F. Buchter, R. Gremaud, A. Remhof, A. Züttel, Chem. A Eur. J. 15, 5531-5534 (2009)

21. O. Friedrichs, J.W. Kim, A. Remhof, D. Wallacher, A. Hoser, Y.W. Cho, K.H. Oh, A. Zuttel, Phys. Chem. Chem. Phys. 12, 4600-4603 (2010)

22. O. Friedrichs, A. Remhof, A. Borgschulte, F. Buchter, S. Orimo, A. Züttel, Phys. Chem. Chem. Phys. 12, 10919-10922 (2010)

23. O. Friedrichs, A. Remhof, S.J. Hwang, A. Züttel, Chem. Mater. 22, 3265-3268 (2010)

24. A. Remhof, Y. Yan, D. Rentsch, A. Borgschulte, C.M. Jensen, A. Zuttel, J. Mater. Chem. A 2, 7244 (2014)

25. A. Remhof, A. Borgschulte, O. Friedrichs, P. Mauron, Y. Yan, A. Züttel, Scr. Mater. 66, 280-283 (2012)

26. C. Pistidda, S. Garroni, F. Dolci, E.G. Bardají, A. Khandelwal, P. Nolis, M. Dornheim, R. Gosalawit, T. Jensen, Y. Cerenius, S. Suriñach, M.D. Baró, W. Lohstroh, M. Fichtner, J. Alloy. Compd. 508, 212-215 (2010)

27. B. Richter, D.B. Ravnsbaek, N. Tumanov, Y. Filinchuk, T.R. Jensen, Dalton Trans. 44, 3988-3996 (2015)

28. Y. Filinchuk, B. Richter, T.R. Jensen, V. Dmitriev, D. Chernyshov, H. Hagemann, Angew. Chem. Int. Ed. 50, 11162-11166 (2011)

29. N.A. Tumanov, D.A. Safin, B. Richter, Z. Lodziana, T.R. Jensen, Y. Garcia, Y. Filinchuk, Dalton Trans. 44, 6571-6580 (2015)

30. M.B. Ley, M. Paskevicius, P. Schouwink, B. Richter, D.A. Sheppard, C.E. Buckley, T.R. Jensen, Dalton Trans. 43, 13333-13342 (2014)

31. T.D. Humphries, M.B. Ley, C. Frommen, K.T. Munroe, T.R. Jensen, B.C. Hauback, J. Mater. Chem. A 3, 691-698 (2015)

32. Y. Sadikin, K. Stare, P. Schouwink, M. Brix Ley, T.R. Jensen, A. Jensen, R. Černý, J. Solid State Chem. 225, 231-239 (2015)

33. R. Černý, P. Schouwink, Y. Sadikin, K. Stare, L.U. Smrčok, B. Richter, T.R. Jensen, Inorg. Chem. 52, 9941-9947 (2013)

34. P. Schouwink, M.B. Ley, T.R. Jensen, L. Smrcok, R. Cerny, Dalton Trans. 43, 7726-7733 (2014)

35. L.H. Jepsen, M.B. Ley, Y. Filinchuk, F. Besenbacher, T.R. Jensen, ChemSusChem 8, 1452-1463 (2015)

36. L.H. Jepsen, M.B. Ley, R. Černý, Y.-S. Lee, Y.W. Cho, D. Ravnsbæk, F. Besenbacher, J. Skibsted, T.R. Jensen, Inorg. Chem. 54, 7402-7414 (2015)
37. D.B. Ravnsbæk, E.A. Nickels, R. Černý, C.H. Olesen, W.I.F. David, P.P. Edwards, Y. Filinchuk, T.R. Jensen, Inorg. Chem. 52, 10877 (2013)

38. C. Frommen, M.H. Sørby, P. Ravindran, P. Vajeeston, H. Fjellvåg, B.C. Hauback, J. Phys. Chem. C 115, 23591-23602 (2011)

39. J.E. Olsen, C. Frommen, T.R. Jensen, M.D. Riktor, M.H. Sørby, B.C. Hauback, RSC Adv. 4, 1570-1582 (2014)

40. M.B. Ley, D.B. Ravnsbæk, Y. Filinchuk, Y.S. Lee, R. Janot, Y.W. Cho, J. Skibsted, T.R. Jensen, Chem. Mater. 24, 1654 (2012)

41. M.B. Ley, S. Boulineau, R. Janot, Y. Filinchuk, T.R. Jensen, J. Phys. Chem. C 116, 21267-21276 (2012)

42. A.V. Skripov, A.V. Soloninin, M.B. Ley, T.R. Jensen, Y. Filinchuk, J. Phys. Chem. C 117, 14965-14972 (2013)

43. D.B. Ravnsbæk, M.B. Ley, Y.-S. Lee, H. Hagemann, V. D'Anna, Y.W. Cho, Y. Filinchuk, T.R. Jensen, Int. J. Hydrogen Energy 37, 8428-8438 (2012)

44. J.E. Olsen, C. Frommen, M.H. Sørby, B.C. Hauback, RSC Adv. 3, 10764-10774 (2013)

45. I. Lindemann, R. Domènech Ferrer, L. Dunsch, Y. Filinchuk, R. Černý, H. Hagemann, V. D’Anna, L.M. Lawson Daku, L. Schultz, O. Gutfleisch, Chem Eur J 16, 8707-8712 (2010)

46. R.D. Shannon, Acta Crystallogr. Sect. A 32, 751-767 (1976)

47. L. Mosegaard, B. Moller, J.-E. Jorgensen, Y. Filinchuk, Y. Cerenius, J.C. Hanson, E. Dimasi, F. Besenbacher, T.R. Jensen, J. Phys. Chem. C 112, 1299-1303 (2008)

48. L.M. Arnbjerg, D.B. Ravnsbæk, Y. Filinchuk, R.T. Vang, Y. Cerenius, F. Besenbacher, J.-E. Jørgensen, H.J. Jakobsen, T.R. Jensen, Chem. Mater. 21, 5772-5782 (2009)

49. O. Zavorotynska, M. Corno, E. Pinatel, L.H. Rude, P. Ugliengo, T.R. Jensen, M. Baricco, Crystals 2, 144 (2012)

50. L.H. Rude, O. Zavorotynska, L.M. Arnbjerg, D.B. Ravnsbæk, R.A. Malmkjær, H. Grove, B.C. Hauback, M. Baricco, Y. Filinchuk, F. Besenbacher, T.R. Jensen, Int. J. Hydrogen Energy 36, 15664-15672 (2011)

51. L.H. Rude, E. Groppo, L.M. Arnbjerg, D.B. Ravnsbæk, R.A. Malmkjær, Y. Filinchuk, M. Baricco, F. Besenbacher, T.R. Jensen, J. Alloy. Compd. 509, 8299-8305 (2011)

52. N. Verdal, T.J. Udovic, J.J. Rush, H. Wu, A.V. Skripov, J. Phys. Chem. C 117(2013), 12010-12011 (2018)

53. J.E. Olsen, M.H. Sørby, B.C. Hauback, J. Alloys Compd. 509, L228-L231 (2011)

54. D.B. Ravnsbæk, L.H. Rude, T.R. Jensen, J. Solid State Chem. 184, 1858-1866 (2011)

55. I. Llamas-Jansa, N. Aliouane, S. Deledda, J.E. Fonneløp, C. Frommen, T. Humphries, K. Lieutenant, S. Sartori, M.H. Sørby, B.C. Hauback, J. Alloy. Compd. 530, 186-192 (2012)

56. J.E. Olsen, M.H. Sørby, B.C. Hauback, J. Alloy. Compd. 509, L228-L231 (2011)

57. H. Grove, L.H. Rude, T.R. Jensen, M. Corno, P. Ugliengo, M. Baricco, M.H. Sørby, B.C. Hauback, RSC Adv. 4, 4736-4742 (2014)

58. L.H. Rude, Y. Filinchuk, M.H. Sørby, B.C. Hauback, F. Besenbacher, T.R. Jensen, J. Phys. Chem. C 115, 7768-7777 (2011)

59. J.Y. Lee, Y.-S. Lee, J.-Y. Suh, J.-H. Shim, Y.W. Cho, Metal halide doped metal borohydrides for hydrogen storage: The case of $\mathrm{Ca}(\mathrm{BH} 4) 2-\mathrm{CaX} 2(\mathrm{X}=\mathrm{F}, \mathrm{Cl})$ mixture. J. Alloys Compd. 506, 721-727 (2010)

60. S. Hino, J.E. Fonneløp, M. Corno, O. Zavorotynska, A. Damin, B. Richter, M. Baricco, T.R. Jensen, M.H. Sørby, B.C. Hauback, J. Phys. Chem. C 116, 12482-12488 (2012)

61. D.A. Sheppard, C. Corgnale, B. Hardy, T. Motyka, R. Zidan, M. Paskevicius, C.E. Buckley, RSC Adv. 4(52), 26552-26562 (2014)

62. H.W. Brinks, A. Fossdal, B.C. Hauback, J. Phys. Chem. C 112, 5658-5661 (2008) 
63. N. Eigen, U. Bösenberg, J. Bellosta von Colbe, T.R. Jensen, Y. Cerenius, M. Dornheim, T. Klassen, R. Bormann, J. Alloy. Compd. 477, 76-80 (2009)

64. L.H. Rude, U. Filso, V. D’Anna, A. Spyratou, B. Richter, S. Hino, O. Zavorotynska, M. Baricco, M.H. Sorby, B.C. Hauback, H. Hagemann, F. Besenbacher, J. Skibsted, T.R. Jensen, Phys. Chem. Chem. Phys. 15, 18185-18194 (2013)

65. R. Heyn, I. Saldan, M.H. Sørby, C. Frommen, B. Arnstad, A.M. Bougza, H. Fjellvåg, B.C. Hauback, Phys. Chem. Chem. Phys. 15, 11226-11230 (2013)

66. C. Pistidda, F. Karimi, S. Garroni, A. Rzeszutek, C. Bonatto Minella, C. Milanese, T.T. Le, L.H. Rude, J. Skibsted, T.R. Jensen, C. Horstmann, C. Gundlach, M. Tolkiehn, P.K. Pranzas, A. Schreyer, T. Klassen, M. Dornheim, J. Phys. Chem. C 118, 28409-28417 (2014)

67. I. Saldan, M. Schulze, C. Pistidda, R. Gosalawit-Utke, O. Zavorotynska, L.H. Rude, J. Skibsted, D. Haase, Y. Cerenius, T.R. Jensen, G. Spoto, M. Baricco, K. Taube, M. Dornheim, J. Phys. Chem. C 117, 17360-17366 (2013)

68. D.B. Ravnsbæk, Y. Filinchuk, R. Cerný, T.R. Jensen, Z. Kristallogr. 225, 557 (2010)

69. L.H. Rude, T.K. Nielsen, D.B. Ravnsbæk, U. Bösenberg, M.B. Ley, B. Richter, L.M. Arnbjerg, M. Dornheim, Y. Filinchuk, F. Besenbacher, T.R. Jensen, Phys. Status Solidi A 208, 1754-1773 (2011)

70. M. Paskevicius, M.B. Ley, D.A. Sheppard, T.R. Jensen, C.E. Buckley, Phys. Chem. Chem. Phys. 15, 19774-19789 (2013)

71. J.Y. Lee, D. Ravnsbæk, Y.-S. Lee, Y. Kim, Y. Cerenius, J.-H. Shim, T.R. Jensen, N.H. Hur, Y.W. Cho, J. Phys. Chem. C 113, 15080-15086 (2009)

72. E.G. Bardají, Z. Zhao-Karger, N. Boucharat, A. Nale, M.J. van Setten, W. Lohstroh, E. Röhm, M. Catti, M. Fichtner, J. Phys. Chem. C 115, 6095-6101 (2011)

73. M. Ley, E. Roedern, P. Thygesen, T. Jensen, Energies 8, 2701 (2015)

74. M.B. Ley, E. Roedern, T.R. Jensen, Phys. Chem. Chem. Phys. 16, 24194-24199 (2014)

75. P.C. Aeberhard, K. Refson, P.P. Edwards, W.I.F. David, Phys. Rev. B 83, 174102 (2011)

76. W.I.F. David, S.K. Callear, M.O. Jones, P.C. Aeberhard, S.D. Culligan, A.H. Pohl, S.R. Johnson, K.R. Ryan, J.E. Parker, P.P. Edwards, C.J. Nuttall, A. Amieiro-Fonseca, Phys. Chem. Chem. Phys. 14(2012), 11800-11801 (1807)

77. L.H. Rude, M. Corno, P. Ugliengo, M. Baricco, Y.S. Lee, Y.W. Cho, F. Besenbacher, J. Overgaard, T.R. Jensen, J. Phys. Chem. C 116, 20239 (2012)

78. S. Aldridge, A.J. Blake, A.J. Downs, R.O. Gould, S. Parsons, C.R. Pulham, J. Chem. Soc. Dalton Trans. (1997) 1007-1012

79. P.H. Bird, M.R. Churchill, Chem. Commun. (London) 8, 403 (1967)

80. R.W. Broach, I.S. Chuang, T.J. Marks, J.M. Williams, Inorg. Chem. 22, 1081 (1983)

81. M. Matsuo, Y. Nakamori, S. Orimo, H. Maekawa, H. Takamura, Appl. Phys. Lett. 224103(1), 224103(3) (2007)

82. H. Maekawa, M. Matsuo, H. Takamura, M. Ando, Y. Noda, T. Karahashi, S. Orimo, J. Am. Chem. Soc. 131, 894-895 (2009)

83. M. Matsuo, H. Takamura, H. Maekawa, H.-W. Li, S. Orimo, Appl. Phys. Lett. 94, 084103(1)-084103(3) (2009)

84. A.V. Skripov, A.V. Soloninin, L.H. Rude, T.R. Jensen, Y. Filinchuk, J. Phys. Chem. C 116, 26177-26184 (2012)

85. P. Schouwink, M.B. Ley, A. Tissot, H. Hagemann, T.R. Jensen, L. Smrčok, R. Černý, Nat. Commun. 5, 5706 (2014)

86. T.K. Nielsen, A. Karkamkar, M. Bowden, F. Besenbacher, T.R. Jensen, T. Autrey, Methods to stabilize and destabilize ammonium borohydride. Dalton Trans. 42, 680-687 (2013)
87. Z. Xiong, C.K. Yong, G. Wu, P. Chen, W. Shaw, A. Karkamkar, T. Autrey, M.O. Jones, S.R. Johnson, P.P. Edwards, Nat. Mater. 7, 138 (2008)

88. K.J. Gross, K.R. Carrington, S. Barcelo, A. Karkamkar, J. Purewal, S. Ma, H. Zhou, P. Dantzer, K. Ott, T. Burrell, T. Semeslberger, Y. Pivak, B. Dam, D. Chandra, Recommended Best Practices for the Characterization of Storage Properties of Hydrogen Storage Materials, National Renewable Energy Laboratory (2012)

89. D.P. Broom, Int. J. Hydrogen Energy 32, 4871-4888 (2007)

90. J. Tomiska, in R.A. Rapp (Ed.), Physicochemical Measurements in Metal Research. Vol. IV, Part I, of R.F. Bunshah (Ed.), Techniques of Metal Reasearch. New York, Interscience Publ. (1970) p. 247

91. L.N.N. Nforbi, A. Talekar, K.H. Lau, R. Chellapa, W.M. Chien, D. Chandra, H. Hagemann, Y. Filinchuk, J.C. Zhao, A. Levchenko, Int. J. Hydrogen Energy 39, 2175-2186 (2014)

92. K. Bohmhammel, B. Christ, G. Wolf, Thermochim. Acta 271, 67-73 (1996)

93. A. El Kharbachi, I. Nuta, F. Hodaj, M. Baricco, Thermochim. Acta 520, 75-79 (2011)

94. J. Hafner, C. Wolverton, G. Ceder, MRS Bull. 31, 659-665 (2006) 95. E.H. Majzoub, V. Ozolinš̌, Phys. Rev. B 77, 104115 (2008)

96. H.L. Lukas, S.G. Fries, B. Sundman, Computational Thermodynamics (Cambridge University Press, Cambridge, 2007)

97. M.W. Chase, NIST-JANAF-Thermochemical Tables, 4th ed. (1998) 98. J.M. Joubert, JOM 64, 1438-1447 (2012)

99. M. Baricco, M. Palumbo, E. Pinatel, M. Corno, P. Ugliengo, Adv. Sci. Technol. 72, 213-218 (2010)

100. A. El Kharbachi, E. Pinatel, I. Nuta, C. Chatillon, M. Baricco, Calphad 39, 80-90 (2012)

101. E.R. Pinatel, E. Albanese, B. Civalleri, M. Baricco, J. Alloy Compd. (2015). doi:10.1016/j.jallcom.2015.01.199

102. J.J. Vajo, C.C. Ahn, R.C. Bowman, B. Fultz, J. Phys. Chem. B 108, 13977-13983 (2004)

103. A.-L. Chaudhary, M. Paskevicius, D.A. Sheppard, C.E. Buckley, Thermodynamic destabilisation of $\mathrm{MgH}_{2}$ and $\mathrm{NaMgH}_{3}$ using group IV elements $\mathrm{Si}$, Ge or Sn. J. Alloys Compd. 623, 109-116 (2015)

104. J.J. Vajo, S.L. Skeith, F. Mertens, J. Phys. Chem. B 109, 3719-3722 (2005)

105. A.T. Luedtke, T. Autrey, Inorg. Chem. 49, 3905-3910 (2010)

106. D. Neiner, A. Karkamkar, M. Bowden, Y.J. Choi, A. Luedtke, J. Holladay, A. Fisher, N. Szymczak, T. Autrey, Energy Environ. Sci. 4, 4187 (2011)

107. D. Wechsler, Y. Cui, D. Dean, B. Davis, P.G. Jessop, J. Am. Chem. Soc. 130, 17195-17203 (2008)

108. T.P. Tiemersma, T. Kolkman, J.A.M. Kuipers, M. van Sint Annaland, Chem. Eng. J. 230(203), 223 (2012)

109. P.G. Campbell, L.N. Zakharov, D.J. Grant, D.A. Dixon, S. Liu, J. Am. Chem. Soc. 132, 3289-3291 (2010)

110. G. Chen, L.N. Zakharov, M.E. Bowden, A.J. Karkamkar, S.M. Whittemore, E.B. Garner, T.C. Mikulas, D.A. Dixon, T. Autrey, S. Liu, J. Am. Chem. Soc. 137, 134-137 (2015)

111. W. Luo, L.N. Zakharov, S. Liu, J. Am. Chem. Soc. 133, 13006-13009 (2011)

112. K. Brooks, M. Bowden, A. Karkamkar, S. Whittemore, T. Autrey, in preparation

113. P. Nordlander, J.K. Norskov, F. Besenbacher, J. Phys. F Metal Phys. 16(9), 1161-1171 (1986)

114. J.K. Norskov, F. Besenbacher, J Less Common Metals 130, 475-490 (1987)

115. Puru Jena, Virginia Commonwealth University, Richmond, VA (to be published)

116. W. Grochala, P.P. Edwards, Chem. Rev. 104, 1283 (2004) 
117. Y. Nakamori, K. Miwa, A. Ninomiya, H. Li, N. Ohba, S. Towata, A. Züttel, S. Orimo, Phys Rev B 74, 045126(1)045126(9) (2006)

118. M.B. Smith, G.E. Bass, J. Chem. Eng. Data 8, 342 (1963)

119. P. Claudy, B. Bonnetot, J.M. Letoffe, G. Turck, Thermochim. Acta 27(1-3), 213-221 (1978)

120. S.C. Abrahams, J.J. Kalnajs, Chem. Phys. 22, 434-436 (1954)

121. T.N. Dymova, D.P. Aleksandrov, V.N. Konoplev, T.A. Silina, N.T. Kuznetsov, Russ. J. Coord. Chem. Koordinatsionnaia Khimiia 19, 529-534 (1993)

122. D.A. Sheppard et al., J. Mater. Chem. A 1, 12775 (2013)

123. T.D. Humphries et al., Chem. Comm. (2015). doi:10.1039/ $\mathrm{c} 5 \mathrm{cc} 03654 \mathrm{~b}$

124. M.P. Pitt et al., J. Am. Chem. Soc. 135, 6930 (2013)

125. H.W. Langmi, G. Sean McGrady, X. Liu, C.M. Jensen, Modification of the $\mathrm{H}_{2}$ desorption properties of $\mathrm{LiAlH}_{4}$ through doping with Ti. J. Phys. Chem. C 114 (23), 10666-10669 (2010)

126. P.E. De Jongh, M. Allendorf, J.J. Vajo, C. Zlotea, Nanoconfined light metal hydrides for reversible hydrogen storage. MRS Bull. 38(6), 488-494 (2013)

127. M. Fichtner, Nanotechnological aspects in materials for hydrogen storage. Adv. Eng. Mater. 7(6), 443-455 (2005)

128. J.J. Vajo, Influence of nano-confinement on the thermodynamics and dehydrogenation kinetics of metal hydrides. Curr. Opin. Solid State Mater. Sci. 15(2), 52-61 (2011)

129. T.K. Nielsen, F. Besenbacher, T.R. Jensen, Nanoconfined hydrides for energy storage. Nanoscale 3(5), 2086-2098 (2011)

130. P.E. De Jongh, P. Adelhelm, Nanosizing and nanoconfinement: new strategies towards meeting hydrogen storage goals. ChemSusChem 3(12), 1332-1348 (2010)

131. C.P. Baldé, B.P.C. Hereijgers, J.H. Bitter, K.P. De Jong, Facilitated hydrogen storage in $\mathrm{NaAlH}_{4}$ supported on carbon nanofibers. Angew. Chem. Int. Ed. 45(21), 3501-3503 (2006)

132. A.F. Gross, J.J. Vajo, S.L. Van Atta, G.L. Olson, Enhanced hydrogen storage kinetics of $\mathrm{LiBH}_{4}$ in nanoporous carbon scaffolds. J. Phys. Chem. C 112(14), 5651-5657 (2008)

133. P. Adelhelm, J. Gao, M.H.W. Verkuijlen, C. Rongeat, M. Herrich, P.J.M. Van Bentum, O. Gutfleisch, A.P.M. Kentgens, K.P. De Jong, P.E. De Jongh, Comprehensive study of melt infiltration for the synthesis of $\mathrm{NaAlH}_{4} / \mathrm{C}$ nanocomposites. Chem. Mater. 22(7), 2233-2238 (2010)

134. P. Błoński, Z. Łodziana, First-principles study of $\mathrm{LiBH}_{4}$ nanoclusters interaction with models of porous carbon and silica scaffolds. Int. J. Hydrogen Energy 39(18), 9848-9853 (2014)

135. R. Bogerd, P. Adelhelm, J.H. Meeldijk, K.P. De Jong, P.E. De Jongh, The structural characterization and $\mathrm{H}_{2}$ sorption properties of carbon-supported $\mathrm{Mg}_{\mathrm{x} 1-\mathrm{x}} \mathrm{Ni}_{\mathrm{x}}$ nanocrystallites. Nanotechnology 20(20), 204019 (2009)

136. C. Zlotea, F. Cuevas, J. Andrieux, C. Matei Ghimbeu, E. Leroy, E. Sengmany, C. Vix-Guterl, R. Gadiou, T. Martens, M. Latroche, Tunable synthesis of (Mg-Ni)-based hydrides nanoconfined in templated carbon studied by in situ synchrotron diffraction. Nano Energy 2(1), 12-20 (2013)

137. Y. Yan, Y.S. Au, D. Rentsch, A. Remhof, P.E. De Jongh, A. Züttel, Reversible hydrogen storage in $\mathrm{Mg}\left(\mathrm{BH}_{4}\right)_{2} /$ carbon nanocomposites. J. Mater. Chem. A 1(37), 11177-11183 (2013)

138. Y.S. Au, Y. Yan, K.P. De Jong, A. Remhof, P.E. De Jongh, Pore confined synthesis of magnesium boron hydride nanoparticles. J. Phys. Chem. C 118(36), 20832-20839 (2014)

139. T.K. Nielsen, U. Bösenberg, R. Gosalawit, M. Dornheim, Y. Cerenius, F. Besenbacher, T.R. Jensen, A reversible nanoconfined chemical reaction. ACS Nano 4(7), 3903-3908 (2010)

140. U. Bösenberg, D.B. Ravnsbæk, H. Hagemann, V. D'Anna, C.B. Minella, C. Pistidda, W. Van Beek, T.R. Jensen, R. Bormann, M. Dornheim, Pressure and temperature influence on the desorption pathway of the $\mathrm{LiBH}_{4}-\mathrm{MgH}_{2}$ composite system. J. Phys. Chem. C 114(35), 15212-15217 (2010)

141. H.S. Lee, Y.S. Lee, J.Y. Suh, M. Kim, J.S. Yu, Y.W. Cho, Enhanced desorption and absorption properties of eutectic LiB ${ }_{4}-\mathrm{Ca}\left(\mathrm{BH}_{4}\right)_{2}$ infiltrated into mesoporous carbon. J. Phys. Chem. C 115(40), 20027-20035 (2011)

142. P. Javadian, D.A. Sheppard, C.E. Buckley, T.R. Jensen, Hydrogen storage properties of nanoconfined $\mathrm{LiBH}_{4}-\mathrm{Ca}\left(\mathrm{BH}_{4}\right)_{2}$. Nano Energy 11, 96-103 (2015)

143. P. Javadian, C. Zlotea, C.M. Ghimbeu, M. Latroche, T.R. Jensen, Hydrogen storage properties of nanoconfined $\mathrm{LiBH}_{4}-\mathrm{Mg}_{2-}$ $\mathrm{NiH}_{4}$ reactive hydride composites. J. Phys. Chem. C 119(11), 5819-5826 (2015)

144. R. Gosalawit-Utke, C. Milanese, P. Javadian, A. Girella, D. Laipple, J. Puszkiel, A.S. Cattaneo, C. Ferrara, J. Wittayakhun, J. Skibsted, T.R. Jensen, A. Marini, T. Klassen, M. Dornheim, $2 \mathrm{LiBH}_{4}-\mathrm{MgH}_{2}-0.13 \mathrm{TiCl}_{4}$ confined in nanoporous structure of carbon aerogel scaffold for reversible hydrogen storage. J. Alloy. Compd. 599, 78-86 (2014)

145. G. Xia, Q. Meng, Z. Guo, Q. Gu, H. Liu, Z. Liu, X. Yu, Nanoconfinement significantly improves the thermodynamics and kinetics of co-infiltrated 2LiBH4-LiAlH4 composites: Stable reversibility of hydrogen absorption/resorption. Acta Mater. 61(18), 6882-6893 (2013)

146. M. Christian, K.F. Aguey-Zinsou, Destabilisation of complex hydrides through size effects. Nanoscale 2(12), 2587-2590 (2010)

147. S. Sartori, K.D. Knudsen, Z. Zhao-Karger, E.G. Bardaji, J. Muller, M. Fichtner, B.C. Hauback, Nanoconfined magnesium borohydride for hydrogen storage applications investigated by SANS and SAXS. J. Phys. Chem. C 114(44), 18785-18789 (2010)

148. S. Sartori, K.D. Knudsen, A. Roth, M. Fichtner, B.C. Hauback, Small-angle scattering investigations on nanoconfined sodium alanate for hydrogen storage applications. Nanosci. Nanotechnol. Lett. 4(2), 173-177 (2012)

149. D.T. Shane, R.L. Corey, C. McIntosh, L.H. Rayhel, R.C. Bowman Jr, J.J. Vajo, A.F. Gross, M.S. Conradi, $\mathrm{LiBH}_{4}$ in carbon aerogel nanoscaffolds: an NMR study of atomic motions. J. Phys. Chem. C 114(9), 4008-4014 (2010)

150. J. Gao, P. Adelhelm, M.H.W. Verkuijlen, C. Rongeat, M. Herrich, P.J.M. Van Bentum, O. Gutfleisch, A.P.M. Kentgens, K.P. De Jong, P.E. De Jongh, Confinement of $\mathrm{NaAlH}_{4}$ in nanoporous carbon: impact on $\mathrm{H} 2$ release, reversibility, and thermodynamics. J. Phys. Chem. C 114(10), 4675-4682 (2010)

151. X. Liu, E.H. Majzoub, V. Stavila, R.K. Bhakta, M.D. Allendorf, D.T. Shane, M.S. Conradi, N. Verdal, T.J. Udovic, S.J. Hwang, Probing the unusual anion mobility of $\mathrm{LiBH}_{4}$ confined in highly ordered nanoporous carbon frameworks via solid state NMR and quasielastic neutron scattering. J. Mater. Chem. A 1(34), 9935-9941 (2013)

152. M.H.W. Verkuijlen, P. Ngene, D.W. De Kort, C. Barré, A. Nale, E.R.H. Van Eck, P.J.M. Van Bentum, P.E. De Jongh, A.P.M. Kentgens, Nanoconfined $\mathrm{LiBH}_{4}$ and enhanced mobility of $\mathrm{Li}^{+}$ and $\mathrm{BH}_{4}{ }^{-}$studied by solid-state NMR. J. Phys. Chem. C 116(42), 22169-22178 (2012)

153. A. Remhof, P. Mauron, A. Züttel, J.P. Embs, Z. Łodziana, A.J. Ramirez-Cuesta, P. Ngene, P. De Jongh, Hydrogen dynamics in nanoconfined lithiumborohydride. J. Phys. Chem. C 117(8), 3789-3798 (2013)

154. P. Ngene, R. Van Zwienen, P.E. De Jongh, Reversibility of the hydrogen desorption from $\mathrm{LiBH}_{4}$ : a synergetic effect of nanoconfinement and $\mathrm{Ni}$ addition. Chem. Commun. 46(43), 8201-8203 (2010)

155. P. Ngene, M.H.W. Verkuijlen, Q. Zheng, J. Kragten, P.J.M. Van Bentum, J.H. Bitter, P.E. De Jongh, The role of Ni in increasing 
the reversibility of the hydrogen release from nanoconfined LiBH4. Faraday Discuss. 151, 47-58 (2011)

156. T.K. Nielsen, M. Polanski, D. Zasada, P. Javadian, F. Besenbacher, J. Bystrzycki, J. Skibsted, T.R. Jensen, Improved hydrogen storage kinetics of nanoconfined $\mathrm{NaAlH}_{4}$ catalyzed with $\mathrm{TiCl}_{3}$ nanoparticles. ACS Nano 5(5), 4056-4064 (2011)

157. K.J. Jeon, H.R. Moon, A.M. Ruminski, B. Jiang, C. Kisielowski, R. Bardhan, J.J. Urban, Air-stable magnesium nanocomposites provide rapid and high-capacity hydrogen storage without using heavy-metal catalysts. Nat. Mater. 10(4), 286-290 (2011)

158. P. Plerdsranoy, N. Wiset, C. Milanese, D. Laipple, A. Marini, T. Klassen, M. Dornheim, R. Gosalawit-Utke, Improvement of thermal stability and reduction of $\mathrm{LiBH}_{4} /$ polymer host interaction of nanoconfined $\mathrm{LiBH}_{4}$ for reversible hydrogen storage. Int. J. Hydrogen Energy 40(1), 392-402 (2015)

159. R.D. Stephens, A.F. Gross, S.L. Van Atta, J.J. Vajo, F.E. Pinkerton, The kinetic enhancement of hydrogen cycling in $\mathrm{NaAlH}_{4}$ by melt infusion into nanoporous carbon aerogel. Nanotechnology 20 (20) (2009)

160. T.K. Nielsen, P. Javadian, M. Polanski, F. Besenbacher, J. Bystrzycki, J. Skibsted, T.R. Jensen, Nanoconfined $\mathrm{NaAlH}_{4}$ : prolific effects from increased surface area and pore volume. Nanoscale 6(1), 599-607 (2014)

161. J. Gao, P. Ngene, M. Herrich, W. Xia, O. Gutfleisch, M. Muhler, K.P. de Jong, P.E. de Jongh, Interface effects in $\mathrm{NaAlH}_{4} /$ carbon nanocomposites for hydrogen storage. Int. J. Hydrogen Energy 39(19), 10175-10183 (2014)

162. P. Ngene, R. Van Den Berg, M.H.W. Verkuijlen, K.P. De Jong, P.E. De Jongh, Reversibility of the hydrogen desorption from $\mathrm{NaBH}_{4}$ by confinement in nanoporous carbon. Energy Environ. Sci. 4(10), 4108-4115 (2011)

163. S. Cahen, J.B. Eymery, R. Janot, J.M. Tarascon, Improvement of the $\mathrm{LiBH}_{4}$ hydrogen desorption by inclusion into mesoporous carbons. J. Power Sources 189(2), 902-908 (2009)

164. X. Liu, D. Peaslee, C.Z. Jost, T.F. Baumann, E.H. Majzoub, Systematic pore-size effects of nanoconfinement of $\mathrm{LiBH}_{4}$ : Elimination of diborane release and tunable behavior for hydrogen storage applications. Chem. Mater. 23(5), 1331-1336 (2011)

165. P.A. Berseth, A.G. Harter, R. Zidan, A. Blomqvist, C.M. Araújo, R.H. Scheicher, R. Ahuja, P. Jena, Carbon nanomaterials as catalysts for hydrogen uptake and release in $\mathrm{NaAIH}_{4}$. Nano Lett. 9(4), 1501-1505 (2009)

166. J. Gao, P. Ngene, I. Lindemann, O. Gutfleisch, K.P. De Jong, P.E. De Jongh, Enhanced reversibility of $\mathrm{H} 2$ sorption in nanoconfined complex metal hydrides by alkali metal addition. J. Mater. Chem. 22(26), 13209-13215 (2012)

167. S. Chumphongphan, U. Fils $\varnothing$, M. Paskevicius, D.A. Sheppard, T.R. Jensen, C.E. Buckley, Nanoconfinement degradation in $\mathrm{NaAlH}_{4} /$ CMK-1. Int. J. Hydrogen Energy 39(21), 11103-11109 (2014)

168. D. Blanchard, A. Nale, D. Sveinbjornsson, T.M. Eggenhuisen, M.H.W. Verkuijlen, T. Vegge, A.P.M. Kentgens, P.E. de Jongh, Nanoconfined LiBH4 as a fast lithium ion conductor. Adv. Funct. Mater. 25(2), 184-192 (2015)

169. R.W.P. Wagemans, J.H. Van Lenthe, P.E. De Jongh, A.J. Van Dillen, K.P. De Jong, Hydrogen storage in magnesium clusters: quantum chemical study. J. Am. Chem. Soc. 127(47), 16675-16680 (2005)

170. W. Lohstroh, A. Roth, H. Hahn, M. Fichtner, Thermodynamic effects in nanoscale NaAlH4. ChemPhysChem 11(4), 789-792 (2010)

171. P. Adelhelm, K.P. De Jong, P.E. De Jongh, How intimate contact with nanoporous carbon benefits the reversible hydrogen desorption from $\mathrm{NaH}$ and $\mathrm{NaAlH}_{4}$. Chem. Commun. 41, 6261-6263 (2009)
172. J.A. Teprovich, M.S. Wellons, R. Lascola, S.-J. Hwang, P.A. Ward, R.N. Compton, R. Zidan, Synthesis and characterization of lithium-doped fullerane $\left(\mathrm{Li}_{\mathrm{x}}-\mathrm{C}_{60}-\mathrm{H}_{\mathrm{y}}\right)$ for reversible hydrogen storage. Nano Lett. 12(2), 582-589 (2012)

173. P. Mauron, M. Gaboardi, D. Pontiroli, A. Remhof, M. Ricco, A. Züttel, Hydrogen desorption kinetics in metal intercalated fullerides. J. Phys. Chem. C 119(4), 1714-1719 (2015)

174. B. Bogdanovic, M. Schwickardi, J. Alloys Compd. 253-254, 1 (1997)

175. B. Bogdanovic, S. Sandrock, Catalyzed complex metal hydrides, MRS BULLETIN/SEPTEMBER 2002, pp 712-716

176. G. Sandrock, K. Gross, G. Thomas, J. Alloys Compd. 339, 299-308 (2002)

177. W. Luo, K.J. Gross, J. Alloys Compd. 385, 224-231 (2004)

178. A. Leon, O. Kircher, M. Fichtner, J. Rothe, D. Schild, J. Phys. Chem. B 110, 1192-1200 (2006)

179. M.P. Pitt, P.E. Vullum, M.H. Sørby, H. Emerich, M. Paskevicius, C.E. Buckley, J. Walmsley, R. Holmestad, B.C. Hauback, Hydrogen absorption kinetics of the transition-metal-chloride enhanced NaAlH4 system. J. Phys. Chem. C 116(27), 14205-14217 (2012)

180. Z.O. Kocabas-Atakli, E. Callini, S. Kato, and A.Züttel, to be submitted to J. Alloys Compd. (2015)

181. Z.Ö.K. Atakli, E. Callini, S. Kato, A. Züttel, Catalyzed hydrogensorption mechanism in alkali alanates, Accepted PCCP (2015)

182. T. Sun, H. Wang, Q. Zhang, D. Sun, X. Yao, M. Zhu, J. Mater. Chem. 21, 9179-9184 (2011)

183. H. Hagemann, R. Cerny, Dalton Trans. 39, 6006-6012 (2010)

184. Z. Lodziana, A. Züttel, P. Zielinski, J. Phys. Condens. Matter 20(46), 465210-465217 (2008)

185. D. Blanchard, Q. Shi, C.B. Boothroyd, T. Vegge, J. Phys. Chem. C 113, 14059-14066 (2009)

186. R.G. Egdell, J.C. Green, Inorg. Chim. Acta 361, 462-466 (2008)

187. C.J. Dain, A.J. Downs, D.W.H. Rankin, Angew. Chem. Int. Ed. Engl. 21(7), 534-535 (1982)

188. E. Callini, A. Borgschulte, C.L. Hugelshofer, A.J. RamirezCuesta, A. Züttel, J. Phys. Chem. C 118, 77-84 (2014)

189. A. Remhof et al., J. Phys: Conf. Ser. 340, 012111-012118 (2012)

190. D.B. Ravnsbæk, L.H Sørensen, Y. Filinchuk, F. Besenbacher, T.R. Jensen, Screening of metal borohydrides by mechanochemistry and diffraction, Angew. Chem. Int. Ed. 51, 3582-3586 (2012)

191. H.-W. Li, Y. Yan, S. Orimo, A. Züttel, C.M. Jensen, Energies 4(1), 185-214 (2011)

192. J.J. Reilly, R.H. Wiswall, Inorg. Chem. 6, 2220-2223 (1967)

193. Y.W. Cho, J.-H. Shim, B.-J. Lee, CALPHAD 30, 65-69 (2006)

194. X.-D. Kang, P. Wang, L.-P. Ma, H.-M. Cheng, Appl. Phys. A Mater. Sci. Process. 89, 963-966 (2007)

195. O. Friedrichs, J.W. Kim, A. Remhof, F. Buchter, A. Borgschulte, D. Wallacher, Y.W. Cho, M. Fichtner, K.H. Oh, A. Zuttel, Phys. Chem. Chem. Phys. 11, 1515-1520 (2009)

196. S.-A. Jin, J.-H. Shim, Y.W. Cho, K.-W. Yi, O. Zabara, M. Fichtner, Scripta Mater. 58, 963-965 (2008)

197. M. Meggouh, D.M. Grant, G.S. Walker, J. Phys. Chem. C 115(44), 22054-22061 (2011)

198. D.B. Ravnsbæk, T.R. Jensen, J. Phys. Chem. Solids 71, 1144-1149 (2010)

199. Y. Kojima, Y. Kawai, M. Matsumoto, T. Haga, J. Alloys Comp. 462, 275-278 (2008)

200. S.-S. Liu, L.-X. Sun, Y. Zhang, F. Xu, J. Zhang, H.-L. Chu, M.Q. Fan, T. Zhang, X.-Y. Song, J.P. Grolier, Int. J. Hydrogen Energy 34, 8079-8085 (2009)

201. D.B. Ravnsbæk, T.R. Jensen, J. Appl. Phys. 111, 112621 (2012) 
202. B.R.S. Hansen, D.B. Ravnsbæk, D. Reed, D. Book, C. Gundlach, J. Skibsted, T.R. Jensen, J. Phys. Chem. C 117, 7423-7432 (2013)

203. S. Soru; A. Taras, C. Pistidda, C. Milanese, M. Bonatto, C. Masolo, P. Nolis, M.D. Baró, A. Marini, M. Tolkiehn, M. Dornheim, S. Enzo, G. Mulas, S. Garroni, S, J. Alloys Compd. 615(S1), S693-S697 (2014)

204. G. Barkhordarian, T. Klassen, M. Dornheim, R. Bormann, J. Alloy. Compd. 440, L18-L21 (2007)

205. U. Bösenberg, S. Doppiu, L. Mosegaard, A. Borgschulte, N. Eigen, G. Barkhordarian, T.R. Jensen, Y. Cerenius, O. Gutfleisch, T. Klassen, M. Dornheim, R. Bormann, Acta Mater. 55, 3951-3958 (2007)

206. J. Jepsen, C. Milanese, A. Girella, G.A. Lozano, C. Pistidda, J.M. Bellosta von Colbe, A. Marini, T. Klassen, M. Dornheim, Int J Hydrogen Energy 38, 8357-8366 (2013)

207. R. Gosalawit-Utke, C. Milanese, T.K. Nielsen, F. Karimi, I. Saldan, K. Pranzas, T.R. Jensen, A. Marini, T. Klassen, M. Dornheim, Int. J. Hydrogen Energy 38, 1932-1942 (2013)

208. M. Hirscher (ed), Strategies to Alter the Reaction Enthalpies of Hydrides in Handbook of Hydrogen Storage (Wiley, Co, Weinheim, 2010)

209. U. Bösenberg, D.B. Ravnsbaek, H. Hagemann, V. D’Anna, C.B. Minella, C. Pistidda, W. Van Beek, T.R. Jensen, R. Bormann, M. Dornheim, J. Phys. Chem. C 114, 15212-15217 (2010)

210. U. Bösenberg, U. Vainio, P.K. Pranzas, J.M. Bellosta von Colbe, G. Goerigk, E. Welter, M. Dornheim, A. Schreyer, R. Bormann, Nanotechnology 20, 204003 (2009)

211. U. Bösenberg, J.W. Kim, D. Gosslar, N. Eigen, T.R. Jensen, J.M. Bellosta von Colbe, Y. Zhou, M. Dahms, D.H. Kim, R. Günther, Y.W. Cho, K.H. Oh, T. Klassen, M. Dornheim, Y.W. Cho, Acta Mater. 58, 3381-3389 (2010)

212. P.E. Pinkerton, M.S. Meyer, J. Alloys Compd. 464, L1 (2008)

213. J.-H. Lim, J.-H. Shim, Y.-S. Lee, Y.W. Cho, J. Lee, Scripta Mater. 59, 1251 (2008)

214. J.-H. Lim, J.-H. Shim, Y.-S. Lee, J.-Y. Suh, Y.W. Cho, J. Lee, Int. J. Hydrogen Energy 35, 6578 (2010)

215. S.-A. Jin, Y.-S. Lee, J.-H. Shim, Y.W. Cho, J. Phys. Chem. C 112, 9520 (2008)

216. P. Mauron, M. Bielmann, A. Remhof, A. Züttel, J.-H. Shim, Y.W. Cho, J. Phys. Chem. C 114, 16801 (2010)

217. J.-H. Shim, Y.-S. Lee, J.-Y. Suh, W. Cho, S.S. Han, Y.W. Cho, J. Alloys Compd. 510, L9 (2012)

218. W. Luo, J. Alloys Compd. 381, 284 (2004)

219. P. Chen, Z. Xiong, J. Luo, J. Lin, K.L. Tan, Nature 420, 302-304 (2002)

220. Z. Xiong, G. Wu, J. Hu, P. Chen, Adv. Mater. 16, 1522-1525 (2004)

221. H.Y. Leng, T. Ichikawa, S. Hino, N. Hanada, S. Isobe, H. Fujii, J. Phys. Chem. B 108, 8763-8765 (2004)

222. Y. Nakamori, G. Kitahara, K. Miwa, N. Ohba, T. Noritake, S. Towata, S. Orimo, J. Alloy. Compd. 404-406, 396-398 (2005)

223. J. Wang, J. Hu, Y. Liu, Z. Xiong, G. Wu, H. Pan, P. Chen, J. Mater. Chem. 19, 2141-2146 (2009)

224. J. Wang, T. Liu, G. Wu, W. Li, Y. Liu, C.M. Araújo, R.H. Scheicher, A. Blomqvist, R. Ahuja, Z. Xiong, P. Yang, M. Gao, H. Pan, P. Chen, Angew. Chem. Int. Ed. 48, 5828-5832 (2009)

225. J. Wang, G. Wu, Y.S. Chua, J. Guo, Z. Xiong, Y. Zhang, M. Gao, H. Pan, P. Chen, ChemSusChem 4, 1622-1628 (2011)

226. J. Hu, Y. Liu, G. Wu, Z. Xiong, Y.S. Chua, P. Chen, Chem. Mater. 20, 4398-4402 (2008)
227. B. Li, Y. Liu, C. Li, M. Gao, H. Pan, J. Mater. Chem. A 2, 3155-3162 (2014)

228. H. Cao, G. Wu, Y. Zhang, Z. Xiong, J. Qiu, P. Chen, J. Mater. Chem. A 2, 15816-15822 (2014)

229. H.-S. Lee, Y.-S. Lee, J.-Y. Suh, M. Kim, J.-S. Yu, Y.W. Cho, J. Phys. Chem. C 115, 20027 (2011)

230. K. Park, H.-S. Lee, A. Remhof, Y.-S. Lee, Y. Yan, M.-Y. Kim, S.J. Kim, A. Züttel, Y.W. Cho, Int. J. Hydrogen Energy 38, 9263 (2013)

231. J.-H. Shim, J.-H. Lim, S. Rather, Y.-S. Lee, D. Reed, Y. Kim, D. Book, Y.W. Cho, J. Phys. Chem. Lett. 1, 59 (2010)

232. K.-B. Kim, J.-H. Shim, Y.W. Cho, K.H. Oh, Chem. Commun. 47, 9831 (2011)

233. J.W. Kim, K.-B. Kim, J.-H. Shim, Y.W. Cho, K.H. Oh, Microsc. Microanal. 20, 1798 (2014)

234. J. Hu, Y. Liu, G. Wu, Z. Xiong, P. Chen, J. Phys. Chem. C 111, 18439 (2007)

235. M. Taube, D. Rippin, W. Knecht, D. Hakimifard, B. Milisavljevic, N. Gruenefelder, A prototype truck powered by hydrogen from organic liquid hydrides. Int. J. Hydrogen Energy 9, 595-599 (1985)

236. S. Hodoshima, H. Arai, S. Takaiwa, Y. Saito, Catalytic decalin dehydrogenation/naphthalene hydrogenation pair as a hydrogen source for fuel-cell vehicle. Int. J. Hydrogen Energy 28, 1255-1262 (2003)

237. M. Chandra, Q. Xu, A high-performance hydrogen generation system: transition metal-catalyzed dissociation and hydrolysis of ammonia-borane. J. Power Sources 156, 190-194 (2006)

238. Z. Huang, X. Chen, T. Yisgedu, J.-C. Zhao, S.G. Shore, Highcapacity hydrogen release through hydrolysis of $\mathrm{NaB}_{3} \mathrm{H}_{8}$. Int. J. Hydrogen Energy 36, 7038-7042 (2011)

239. D. Schubert, D. Neiner, M. Bowden, S. Whittemore, J. Holladay, Z. Huang, T. Autrey, Capacity enhancement of aqueous borohydride fuels for hydrogen storage in liquids. J. Alloys Compd. 645 (Supplement 1), S196-S199 (2015). doi:10.1016/j. jallcom.2015.01.063

240. A. Cooper, Design and development of new carbon-based sorbent Systems for an effective containment of hydrogen. Technical Report, DOE Award No. DE-FC36-04GO14006, Department of Energy, Washington, DC (2012), pp 2231-2233

241. P.G. Campbell, L.N. Zakharov, D.J. Grant, D.A. Dixon, S.-Y. Liu, Hydrogen storage by Boron-Nitrogen heterocycles: a simple route for spent fuel regeneration. J. Am. Chem. Soc. 132(10), 3289-3291 (2010)

242. S. Whittemore, M. Bowden, A. Karkamkar, K. Parab, D. Neiner, S.-Y. Liu, D. Dixon, T. Autrey, Exploring the use of carbon, nitrogen, and boron containing heterocycles in liquid hydrogen storage. in ACS Division of Fuel Chemistry Proceedings (2014)

243. Z. Wang, J. Belli, C.M. Jensen, Homogenous dehydrogenation of liquid organic carriers catalyzed by an iridium PCP complex. Faraday Discuss. 151, 297-305 (2011)

244. S. Orimo, Y. Nakamori, J.R. Eliseo, A. Züttel, C.M. Jensen, Chem. Rev. 107, 4111-4132 (2007)

245. D.K. Slattery, M.D. Hampton, Complex hydrides for hydrogen storage. in Proceedings of the 2002 U.S. Hydrogen Program Review, NREL/CP-610-32405, pp 1-9 (2002)

246. E. Ashby, W. Foster, Concerning the existence of "triple metal hydrides". The reactions of lithium aluminum hydride with diborane. J. Am. Chem. Soc. 88(14), 3248-3255 (1966)

247. A.J. Downs, L.A. Jones, Polyhedron 13, 2401 (1994) 